\title{
W4-11: a high-confidence benchmark dataset for computational thermochemistry derived from first-principles W4 data
}

\author{
Amir Karton ${ }^{\dagger}$, Shauli Daon ${ }^{\sharp}$, and Jan M. L. Martin ${ }^{\ddagger *}$ \\ ${ }^{\dagger}$ School of Chemistry, University of Sydney, Sydney, NSW 2006, Australia. \\ ${ }^{\sharp}$ Department of Organic Chemistry, \\ Weizmann Institute of Science, IL-76100 Rehovot, Israel. \\ ${ }^{\ddagger}$ Department of Chemistry, University of North Texas, Denton, TX 76203-5017, USA.
}

(Dated: CPLETT-11-515: Revised manuscript May 3, 2011)

\begin{abstract}
We show that the purely first-principles Weizmann-4 (W4) computational thermochemistry method developed in our group can reproduce available Active Thermochemical Tables atomization energies for 35 molecules with a $3 \sigma$ uncertainty of under $1 \mathrm{~kJ} / \mathrm{mol}$. We then employ this method to generate the W4-11 dataset of 140 total atomization energies of small first-and second-row molecules and radicals. These cover a broad spectrum of bonding situations and multireference character, and as such are an excellent, quasi-automated benchmark (available electronically as supporting information) for parametrization and validation of more approximate methods (such as DFT functionals and composite methods). Secondary contributions such as relativity can be included or omitted at will, unlike with experimental data. A broad variety of more approximate methods is assessed against the W4-11 benchmark and recommendations are made.
\end{abstract}

\section{Cite as:}

A. Karton, S. Daon, J. M. L. Martin. Chem. Phys. Lett. 510, 165-178 (2011). http://dx.doi.org/10.1016/j.cplett.2011.05.007 


\section{Author biographies}

Amir Karton was born in Israel in 1974. He obtained his B.Sc. in chemistry from BenGurion U. in 2002 and his M.Sc. (2005) and Ph.D. (2010) from the Weizmann Institute of Science, both in the Martin group. His Ph.D. thesis won the Dov Elad Memorial Prize. He is presently an ARC Discovery Postdoctoral fellow with Leo Radom at the University of Sydney and the ARC Centre of Excellence for Free Radical Chemistry and Biotechnology.

Shauli Daon was born in Israel. After spending 1999-2003 in the Israel Defense Forces as a programmer, he obtained his B.Sc. in biomedical engineering from Tel-Aviv University in 2007 (working simultaneously at a start-up company) and his M.Sc. in Chemistry in 2009-10 from the same institution (in the lab of Uzi Even). He is currently working on his Ph.D. at the Weizmann Institute, divided between the groups of Jan Martin and of Eli Pollak.

Jan (Gershom) Martin was born in Belgium in 1964 and obtained his M.Sc. (1987) and Ph.D. (1991) from U. of Antwerp. Following postdoctoral work in California with T.J. Lee and P.R. Taylor, he became a tenured researcher with Belgium's NSF. In 1996 he joined the Weizmann Institute of Science in Israel, being promoted to associate professor in 2001 and full professor in 2005. In late 2010 he became a Distinguished University Professor at the University of North Texas. He has (co-)authored over 230 papers, which have been cited about 10,000 times. Prizes include the 2004 Dirac Medal and 2008 Wolgin Prize. 


\section{INTRODUCTION}

Over the last two decades there has been a proliferation in the number of approximate theoretical methods, in particular density functional theory (DFT) and, to a lesser extent, composite thermochemical procedures.

At present, the only validation for a given approximate method is benchmarking against reference data with well-defined error bars that are much smaller (preferably, by an order of magnitude or more) than the intrinsic error of the method being evaluated. In addition, many of these approximate methods include some adjustable parameters (in some cases, dozens). In some cases (e.g.,[1, 2]), these can be determined from formal considerations (e.g., obeisance of certain boundary conditions by an exchange-correlation functional). In most other cases (e.g., [3 8]), parameters are adjusted for minimal RMS error over one or more reference datasets, in which case accuracy of these reference data becomes even more imperative. It is no less imperative, however, that these sets be as large and chemically diverse as reasonably possible in order not to end up with a "glorified interpolation scheme" through sample bias.

Historically, much work relied on various sets of thermochemical data derived from experiment. Most notably, this was the case in the $\mathrm{G} n$ family of composite ab initio methods developed by Pople and coworkers [9-15], and many researchers (the wildly popular B3LYP method[3, 16] being the most famous example) relied on the datasets developed by this group. [14, 17-19] (Most of the data were compiled from the JANAF tables[20] and their successor, the NIST WebBook[21].) The more recent CCCBDB initiative[22] at NIST must also be mentioned in this context. However, as time progressed, limitations of purely experimental benchmark data became more apparent. These include but are not limited to:

- uncertainties in the measurements exceeding $1 \mathrm{kcal} / \mathrm{mol}$ except for a small subset. This was a nonissue as long as intrinsic method errors were in the 5-10 kcal/mol range or even greater (e.g., for semiempirical methods [23] and simple GGA density functionals), but with both composite ab initio schemes and more sophisticated density functional methods, this becomes a significant issue;

- the experimental data contain secondary contributions that are not included - or cannot efficiently be included during parametrization — in the approximate models. 
These range from relativistic effects and anharmonic zero-point vibrational energies for thermochemistry to tunneling and recrossing corrections for barrier heights;

- availability of reliable experimental data is unevenly spread both throughout the periodic table and, more generally, the chemical universe. For some types of compounds of chemical interest, insufficient data will be available, or even none at all. In fact, the toxicity or excessive reactivity of some compounds may discourage or preclude reliable measurements;

- as experimental chemical thermodynamics is no longer a fashionable research subject, few new data are being generated.

High-accuracy $a b$ initio methods have now reached a point where, for small molecules, accuracies can be achieved that rival all but the most reliable experiments. For instance, Weizmann-4 theory[24, 25] (W4) can, for total atomization energies (TAE values, $\sum D_{e}$ ) of small molecules of the first and second row of the Periodic Table, offer data with $95 \%$ confidence intervals narrower than $1 \mathrm{~kJ} / \mathrm{mol}$, which is an order of magnitude better than can be achieved with any present-day functional. The "competing" HEAT approach developed by an international consortium of researchers [26 28] offers similar accuracy for first-row systems. Neither W4 or HEAT rely on any adjustable parameters derived from experiment. (See also Refs. [29, 30] for related approaches.)

While datasets obtained from high-accuracy ab initio calculations can eminently serve as "secondary standards" (to borrow a term from analytical chemistry), for the initial validation of the methods, an even more accurate "primary standard" is imperative. Both W4 and HEAT relied for this on comparatively small sets of very accurate experimental data obtained from the Active Thermochemical Tables 31 33] (ATcT) thermochemical network developed by Ruscic and coworkers.

A number of accurate reference datasets have been proposed in recent years, covering a wide range of species and chemical properties. For instance, Truhlar and coworkers put forward benchmark sets for various types noncovalent interactions [34 38] as well as, notably, the HTBH38 and NHTBH38 (38 hydrogen- and nonhydrogen-transfer barrier heights [39]) and especially DBH24 (Diverse Barrier Heights) [40] dataset for thermochemical kinetics. Hobza and coworkers put forward the widely employed S22 set of weak interaction data[41, 42]. Datasets have been advanced for alkane thermochemistry[43] and alkane 
conformer energies [44]. Coming to the present subject our group proposed[8] the W4-08 (Weizmann 4-2008) dataset of 99 W4-level molecular TAEs covering the first and second rows, as well as spanning a broad range in terms of the severity of nondynamical correlation effects. These and other datasets were integrated into the GMTK30 general-purpose reference dataset proposed by Grimme and coworkers[45]. (One noteworthy additional component is a "mindless" benchmark[46] of data for purely artificial structures, which has the benefit of being devoid of chemical bias.)

As computational resources expanded on the one hand, and additional ATcT data became available on the other hand, we are in a position to significantly extend our earlier work.

In this article we shall first "re-establish" the reliability of Weizmann-4 theory against a set of 35 highly accurate experimental atomization energies (with associated error bars narrower than $0.05 \mathrm{kcal} / \mathrm{mol}$ ) available from the Active Thermochemical Tables, ATcT, paradigm of Ruscic et al. [31 33]. We proceed by extending the W4-08 [8] dataset of 99 total atomization energies of small first- and second-row species to include 140 atomization energies (with up to five heavy atoms), all of which are obtained by means of the W4 (or higher) ab initio computational thermochemistry protocol. For the purpose of testing/parametrizing more approximates electronic structure methods, the following subsets of reaction energies are also formed: bond dissociation (99 reactions), heavy-atom transfer (707 reactions), isomerization (20 reactions), and nucleophilic substitution (13 reactions). Finally, we shall consider performance of a number of approximate methods. Our new W411 dataset is made available in machine-readable form as electronic supporting information to the present paper.

\section{COMPUTATIONAL METHODS}

All calculations were performed on the Martin group Linux cluster and on the Faculty of Chemistry HPC facility at the Weizmann Institute of Science. SCF, CCSD, and CCSD(T) calculations were carried out using MOLPRO 2009.1 [47], while for post-CCSD(T) calculations, the string-based general coupled cluster code MRCC [48, 49] was employed, interfaced to the CFOUR program suite[50]. The diagonal Born-Oppenheimer corrections (DBOC) were carried out using CFOUR. All basis sets involved belong to the correlation consistent family of Dunning and co-workers[51 55]. The notation aug'-cc-pV $(n+\mathrm{d}) \mathrm{Z}$ 
indicates the combination of regular cc-pVnZ on hydrogen and aug-cc-pV $(n+\mathrm{d}) \mathrm{Z}$ on other elements.

Weizmann-4 (W4) theory represents a layered extrapolation to the all-electron, relativistic CCSDTQ5 infinite basis set limit energy, and has been specified and rationalized in great detail elsewhere[24]. In short, the W4 computational protocol involves the following steps:

- The ROHF-SCF contribution is extrapolated from the aug'-cc-pV $(5+\mathrm{d}) \mathrm{Z}$ and aug'-cc-pV(6+d)Z basis sets using the Karton-Martin modification[56] of Jensen's extrapolation formula[57].

- The RCCSD valence correlation energy is calculated from these same basis sets. Following the suggestion of Klopper [58], it is partitioned into singlet-coupled pair energies, triplet-coupled pair energies, and $\hat{T}_{1}$ terms. The singlet-coupled and tripletcoupled pair energies are extrapolated using the $A+B / L^{\alpha}$ two-point extrapolation formula (where $L$ is the highest angular momentum present in the basis set) with $\alpha_{S}=3$ and $\alpha_{T}=5$, respectively, and the $\hat{T}_{1}$ term (which exhibits very weak basis set dependence) is set equal to that in the largest basis set.

- The $(\mathrm{T})$ valence correlation energy is extrapolated from the aug'-cc-pV $(\mathrm{Q}+\mathrm{d}) \mathrm{Z}$ and aug'-cc-pV $(5+\mathrm{d}) \mathrm{Z}$ basis sets using the $A+B / L^{3}$ two-point extrapolation formula. For open-shell systems the Werner-Knowles-Hampel[59] (a.k.a. MOLPRO) definition of the restricted open-shell $\operatorname{CCSD}(\mathrm{T})$ energy is employed throughout, rather than the original Watts-Gauss-Bartlett[60] (a.k.a. ACES II/CFour) definition.

- The higher-order connected triples, $\hat{T}_{3}-(\mathrm{T})$, valence correlation contribution is extrapolated from the cc-pVDZ and cc-pVTZ basis sets using the $A+B / L^{3}$ two-point extrapolation formula.

- The connected quadruples, $\hat{T}_{4}$, is partitioned into the valence correlation $\hat{T}_{4}-(\mathrm{Q})$ and (Q) contributions. Which are calculated with the cc-pVDZ and cc-pVTZ basis sets, respectively. In refs. [24, 25] we showed that scaling their sum by 1.10 offers a very reliable (as well as fairly cost-effective) estimate of the basis set limit $\hat{T}_{4}$ contribution.

- The connected quintuples, $\hat{T}_{5}$, contribution converges very rapidly with the basis set, as it primarily represents static rather than dynamic correlation [24, 25]. The 
$\hat{T}_{5}$ contribution is calculated with the $s p$ part of cc-pVDZ, this truncated basis set being denoted cc-pVDZ(no $d)$.

- The CCSD(T) inner-shell contribution is extrapolated from the aug'-cc-pwCVTZ and aug'-cc-pwCVQZ core-valence basis sets[54] using the $A+B / L^{3}$ two-point extrapolation formula.

- The scalar relativistic contribution (in the second-order Douglas-Kroll-Hess approximation [61, 62]) is obtained from the difference between non-relativistic $\operatorname{CCSD}(\mathrm{T}) / \mathrm{aug}$ 'pV $\left.^{\mathrm{Q}} \mathrm{Q}+\mathrm{d}\right) \mathrm{Z}$ and relativistic $\operatorname{CCSD}(\mathrm{T}) / \mathrm{aug}^{\prime}-\mathrm{cc}-\mathrm{pV}(\mathrm{Q}+\mathrm{d}) \mathrm{Z}-\mathrm{DK}$ calculations[55].

- Atomic and molecular first-order spin-orbit coupling terms are taken from the experimental fine structure.

- Finally, the diagonal Born-Oppenheimer correction (DBOC) is calculated at the ROHF/AVTZ level of theory.

For the largest systems considered in the present work, namely $\mathrm{CH}_{3} \mathrm{C}(=\mathrm{O}) \mathrm{OH}, \mathrm{CH}_{3} \mathrm{CH}_{2} \mathrm{OH}$ and $\mathrm{CH}_{3} \mathrm{CH}_{2} \mathrm{~F}$, some of the post-CCSD(T) calculations proved to be too taxing even for our most powerful machines (8 core, Nehalem X55502.66 GHz, with 72 GB of RAM, and 4 TB hard drive). Therefore, the hydrogen basis sets were truncated in the post-CCSD(T) steps in the following cases:

- In the valence CCSDT calculations for acetic acid, ethanol, and fluoroethane, $d$ functions were omitted from the cc-pVTZ basis set, the resulting truncated basis set being denoted PVTZ(no $d$ on $\mathrm{H})$.

- In the valence CCSDTQ calculations for ethanol and fluoroethane, $p$ functions were omitted from cc-pVDZ, the resulting truncated basis set being denoted PVDZ(no $p$ on $\mathrm{H})$.

From our experience this truncation of the basis sets has little (or no) visible effect on the above post-CCSD $(\mathrm{T})$ contributions 63 . In addition, the $\hat{T}_{4}$ contribution for acetic acid is taken from W4lite theory, i.e., $\hat{T}_{4}=\operatorname{CCSDT}(\mathrm{Q}) / \mathrm{cc}-\mathrm{pVDZ}-\mathrm{CCSDT} / \mathrm{cc}-\mathrm{pVDZ}$. This approximation should be of little consequence as the $\% \mathrm{TAE}_{e}[(\mathrm{~T})]$ diagnostic for this system is just $2.0 \%$ (vide infra). 
In section IIID we compare the relative performance of different DFT exchangecorrelation functionals in predicting the reaction energies in the W4-11 dataset. The exchange-correlation functionals employed include the following classes (numbered by the rungs on Perdew's 'Jacob's Ladder of DFT' [64] they belong to):

1. the local density approximation (LDA), specifically SVWN5[65];

2. the pure generalized gradient approximation (GGA) functionals, employing both the local density and the reduced density gradient: B97-D [66], BLYP 67, 68], HCTH407 [69], and PBE[1];

3. the meta-GGAs, additionally employing the kinetic energy density $\tau$ (which contains similar information as the Laplacian of the density): M06-L[70], TPSS[2] and $\tau$ $\mathrm{HCTH[71]}$;

4. functionals involving the occupied orbitals, specifically hybrid functionals (involving HF-like exchange) subdivided into

(4a) the hybrid GGAs (which one might term 'imperfect fourth-rung functionals'): BH\&HLYP [72, B3LYP [3, 16, 68, B3P86[3, 73], B3PW91 [3, 74], X3LYP[75], B97-1 [4], and PBE0[76]. We also consider the range-separated hybrid GGAs $\omega \mathrm{B} 97[77]$, and $\omega \mathrm{B} 97-\mathrm{X}[77]$;

(4b) the hybrid meta-GGAs: TPSSh[78], B1B95[79], PW6B95[37], $\tau$-HCTHh[71], BMK[80, M06, M06-2X, and M06-HF [5-7].

5. employing also virtual orbital information, double-hybrid functionals (involving both HF-like exchange and MP2-like correlation): B2-PLYP[81], ROB2-PLYP[82], mPW2PLYP 83], B2T-PLYP 84], B2K-PLYP 84], B2GP-PLYP[8], and DSD-BLYP [85].

For functionals on rungs $1-4$, we used the aug'-pc-3+d basis set of Jensen[86], which is of $[6 s 5 p 4 d 2 f 1 g]$ quality but optimized for Hartree-Fock and DFT. In contrast, for the double hybrids, which exhibit slower basis set convergence owing to the MP2-like correlation term, we use the aug'-pc-4 basis set. The notation aug'-pc- $n$ indicates the combination of regular pc- $n$ on hydrogen and aug-pc- $n$ on other elements. The ' $+d$ ' suffix indicate the addition of high-exponent $d$ functions on second-row elements (with exponents in an even-tempered series with stride 2.5) [87]. 
Finally, we evaluate the performance of a representative set of contemporary empirical and nonempirical compound thermochemistry methods. These include: (a) the Gaussian$n$ methods G3B3[88], G3(MP2)B3[88], G4[12], G4(MP2) [89], and G4(MP2)-6X[90]; (b) Petersson's CBS-QB3[91] method and its variant ROCBS-QB3[92]; (c) the Wilson group ccCA[93 95] (correlation consistent composite approach) as well as its more recent variant ccCA-PS3 [96, 97]; and (d) Weizmann-1 (W1) [98] as implemented [99] in Gaussian 09.[100] All the DFT and composite thermochemical calculations were carried out using Gaussian 09, except for the ccCA calculations which were carried out using MOLPRO 2010.1 and automated in that program's scripting language. While (a) and (b) all include empirical correction terms and factors of some form, neither ccCA nor W1 include parameters derived from experiment, although $\mathrm{W} 1$ does include two parameters derived from more rigorous calculations.

\section{RESULTS AND DISCUSSION}

In this work, we add 41 small to medium sized species to the our W4-08 dataset of 99 total atomization energies for first- and second-row species [8]. The earlier W4-08 dataset contains only a handful of non-hydrocarbon organic functionalities (mainly, a few amine and imine species), therefore, in the present work we have added 28 organic compounds: fluoroalkanes (9), alcohols (4), carboxylic acids (2), aldehyde (1), dialdehyde (1), epoxides (2), cyclic peroxide (1), ketene (1), imine (3), cyanates (2), nitroso (1), and hydrocarbon (1). We have also added 9 inorganic compounds, most notably: hydrogen azide, cis/transnitrous acid, cis/trans-hydrotrioxy radical, tetrafluorosilane, and chloramine. Finally, we add 4 hydrocarbon species (propane, propene, propyne and allene), W4 data on which were previously reported in Ref.[43]. The resulting dataset includes a total of 140 neutral species: closed shell (106), radicals (27), and triplet systems (7). We note that of the closed shell species, nine are singlet carbenes. The final set includes: hydrogen-containing (84), hydrogen-free (56), organic (59), and inorganic compounds (81), with single and multiple bonds that involve varying degrees of covalent and ionic characters. This set evidently spans the gamut from systems dominated by a single reference configuration (such as $\mathrm{H}_{2} \mathrm{O}$ and $\mathrm{CH}_{4}$ ) to systems dominated by nondynamical correlation (such as $\mathrm{F}_{2} \mathrm{O}_{2}, \mathrm{O}_{3}$, and $\mathrm{BN}^{1} \Sigma^{+}$). In terms of elemental composition the dataset includes: first-row species (99), second-row 
species (19), mixed first- and second-row species (21), and dihydrogen. Table I lists the set of 140 molecules in the W4-11 dataset.

\section{A. Multireference considerations}

Table II provides the percentage of the total atomization energy accounted for by the SCF, (T) triples, post-CCSD $(\mathrm{T})$ (i.e., $\left.\left[\hat{T}_{3}-(\mathrm{T})+\hat{T}_{4}+\hat{T}_{5}\right]\right)$, and $\left[\hat{T}_{4}+\hat{T}_{5}\right]$ contributions from W4 theory (as well as the coupled cluster $\mathcal{T}_{1}$ and $\mathcal{D}_{1}$ diagnostics 101 103]) for the 37 systems that were added to the W4-11 dataset in the present work. Diagnostics for the entire W411 set are included as Supporting Information (Table SI-I). For thermochemical purposes, the $\% \operatorname{TAE}_{e}\left[\hat{T}_{4}+\hat{T}_{5}\right]$, i.e., the percentage of the total atomization energy accounted for by the connected quadruple and quintuple excitations, provides the best a posteriori measure of nondynamical correlation effects [24, 104]. Table II presents the squared correlation coefficients $\left(\mathrm{R}^{2}\right)$ between the $\% \mathrm{TAE}_{e}\left[\hat{T}_{4}+\hat{T}_{5}\right]$ metric and the other diagnostics over the whole W4-11 dataset of 140 species. For the $\% \operatorname{TAE}_{e}[(\mathrm{~T})]$ diagnostic we obtain the same $\mathrm{R}^{2}$ value (0.94) that was obtained in ref. [24] for a much smaller set of molecules, thus confirming that $\% \operatorname{TAE}_{e}[(\mathrm{~T})]$ serves as a reliable diagnostic for the importance of nondynamical correlation. We also note that the coupled cluster $\mathcal{T}_{1}$ and $\mathcal{D}_{1}$ diagnostics do not correlate well with the $\% \operatorname{TAE}_{e}\left[\hat{T}_{4}+\hat{T}_{5}\right]$ metric $\left(\mathrm{R}^{2}=0.38\right.$ and 0.33 , respectively). In the context of the present work, we note that $\% \operatorname{TAE}_{e}[(\mathrm{~T})]$ values higher than $5 \%$ are obtained for five inorganic species: cis- $\mathrm{HON}=\mathrm{O}(5.3 \%)$, trans- $\mathrm{HON}=\mathrm{O}(5.4 \%), \mathrm{HN}_{3}(5.6 \%)$, cis- $\mathrm{HO}_{3} \cdot(7.4 \%)$, and trans- $\mathrm{HO}_{3}$. (7.9\%). All new systems are bound at the SCF level $\left(\% \mathrm{TAE}_{e}[(\mathrm{SCF})]=24.0-53.3 \%\right.$, see Table II .

The $\% \mathrm{TAE}_{e}$ percentages in Table $\mathrm{II}$ are relative to non-relativistic, valence CCSDTQ5 atomization energies from W4 theory. However, an a priori \% $\mathrm{TAE}_{e}[(\mathrm{~T})]$ diagnostic, which for all intents and purposes would give the same results[105], is given by:

$$
\% \operatorname{TAE}_{\mathrm{e}}[(T)]=100 \times \frac{\mathrm{TAE}_{e}[\mathrm{CCSD}(\mathrm{T})]-\mathrm{TAE}_{e}[\mathrm{CCSD}]}{\mathrm{TAE}_{e}[\mathrm{CCSD}(\mathrm{T})]}
$$

where $\mathrm{TAE}_{e}[\mathrm{CCSD}]$ and $\mathrm{TAE}_{e}[\mathrm{CCSD}(\mathrm{T})]$ represent, respectively, valence $\mathrm{CCSD}$ and $\operatorname{CCSD}(\mathrm{T})$ electronic atomization energies. Reference[24 gives useful criteria for interpretation of the $\% \operatorname{TAE}_{e}[(\mathrm{~T})]$ values: below $2 \%$ indicates systems dominated by dynamical correlation; $2-5 \%$ mild nondynamical correlation; $5-10 \%$ moderate nondynamical 
correlation; and in excess of $10 \%$ severe nondynamical correlation.

It is of interest to examine the basis set dependence of the $\% \mathrm{TAE}_{e}[(\mathrm{~T})]$ diagnostic (given by eq. 1). Table III gives the error statistics (over the molecules in the W4-11 test set) for the $\% \mathrm{TAE}_{e}[(\mathrm{~T})]$ diagnostic calculated with the $\mathrm{AV} n \mathrm{Z}(n=\mathrm{D}, \mathrm{T}, \mathrm{Q}$, and 5$)$ basis sets with respect to basis set limit values from W4 theory. It is evident that the $\% \mathrm{TAE}_{e}[(\mathrm{~T})]$ diagnostic exhibits a relatively weak basis set dependence, e.g., RMSD of $0.78 \%$ (AVDZ), $0.15 \%$ (AVTZ), $0.08 \%$ (AVQZ), and $0.06 \%$ (AV5Z) are obtained with respect to the basis set limit values from W4 theory. Thus, it seems that values obtained with the AVTZ basis set are sufficiently converged for practical purposes, and even the AVDZ values are generally within $1 \%$ of the basis set limit values (for pathologically multireference cases such as FOO and FOOF the deviation may reach up to $2 \%$ ).

\section{B. Validation of $\mathbf{W} n$ theories}

Table IV]lists the component breakdown of the final W4 total atomization energies at the bottom of the well $\left(\mathrm{TAE}_{e}\right)$ for the 37 new species considered in the present work. The W4 (or higher) components for the entire W4-11 set are given as Supporting Information (Table SI-II). It is worth noting that for most systems higher-order triple excitations, $\hat{T}_{3}-(\mathrm{T})$, and

the post-CCSDT excitations, $\hat{T}_{4}+\hat{T}_{5}$, tend to largely cancel one another (they are of similar orders of magnitude, but $\hat{T}_{4}+\hat{T}_{5}$ universally increase the atomization energy while $\hat{T}_{3}-(\mathrm{T})$ generally decrease it). However, for the five species with $\% \mathrm{TAE}_{e}[(\mathrm{~T})] \geq 5 \%$ (vide supra) as well as for $\mathrm{SiF}_{4}$ the sum of the post-CCSD(T) contributions amounts (in absolute value) to more than half a kcal/mol: cis-HON=O $(+0.66)$, trans-HON=O $(+0.75), \mathrm{HN}_{3}(+0.76)$, cis- $\mathrm{HO}_{3}(+1.85)$, trans- $\mathrm{HO}_{3}(+2.31)$, and $\mathrm{SiF}_{4}(-0.67 \mathrm{kcal} / \mathrm{mol})$.

A comparison between the final $\mathrm{W} 4$ values at $0 \mathrm{~K}\left(\mathrm{TAE}_{0}\right)$ and the Active Thermochemical Tables data for the 37 systems added in the present work is given in Table $\mathrm{V}$, whereas a comparison for the entire W4-11 set is given as Supporting Information (Table SI-III). Experimental atomization energies from ATcT with associated 95\% confidence intervals equal to (or narrower than) $0.05 \mathrm{kcal} / \mathrm{mol}$ are available in the literature for 36 species.[24, 25, 104, 106, 107. Of these, an unusually large discrepancy between the W4 and ATcT (of $0.50 \mathrm{kcal} / \mathrm{mol}$ ) is found for hydrazine. This discrepancy is unexpected since this system does not exhibit strong nondynamical correlation effects $\left(\% \mathrm{TAE}_{e}[(\mathrm{~T})]=1.9 \%, \hat{T}_{4}=0.43\right.$, and $\hat{T}_{5}$ 
$=0.02 \mathrm{kcal} / \mathrm{mol}$ ) and the uncertainty in our ZPVE can only account for a fraction of this gap. Klopper and coworkers, both using Gaussian basis sets [106] and using explicitly correlated methods [108], found results similar to our own for this molecule, which suggests the ATcT value might be reconsidered. For the rest of the 35 highly accurate ATcT atomization energies there is excellent agreement between W4 and experiment (ATcT). W4 theory attains an RMSD of $0.085 \mathrm{kcal} / \mathrm{mol}$ and a MAD of $0.065 \mathrm{kcal} / \mathrm{mol}$ (implying a $95 \%$ confidence interval of about $0.17 \mathrm{kcal} / \mathrm{mol})$. A MSD of $-0.011 \mathrm{kcal} / \mathrm{mol}$ suggests that $\mathrm{W} 4$ theory is free of systematic bias. These error statistics are identical to those obtained in the original W4 paper 24] for a dataset of about half the size $(\mathrm{RMSD}=0.085$, $\mathrm{MAD}=0.066$, and MSD $=-0.011)$. Forty five ATcT atomization energies are associated with $95 \%$ confidence intervals $\leq 0.10 \mathrm{kcal} / \mathrm{mol}$. For this extended evaluation test set W4 theory affords an RMSD of 0.102 , a MAD of 0.080 , and a MSD of $-0.008 \mathrm{kcal} / \mathrm{mol}$. We note, however, that for all these systems the discrepancy between W4 and experiment is still below the threshold of "benchmark accuracy" (arbitrarily defined as $1 \mathrm{~kJ} / \mathrm{mol}=0.24 \mathrm{kcal} / \mathrm{mol}$ ). In particular, the largest deviations (theory-experiment) being: -0.23 (ozone), -0.21 (formic acid), +0.20 (trans-nitrous acid and cis-nitrous acid), and $+0.22 \mathrm{kcal} / \mathrm{mol}$ (propane). Ozone represents an extremely challenging system for single reference methods due to its notoriously multireference character (e.g., $\left.\% \mathrm{TAE}_{e}[(\mathrm{~T})]=17.4 \%\right)$. Including a $\hat{T}_{3}-(\mathrm{T})$ correction to the core-valence contribution computed with the cc-pwCVTZ basis set (i.e., W4.2 theory) narrows the gap between theory and experiment for ozone by $0.10 \mathrm{kcal} / \mathrm{mol}$. Additional upgrading of the basis sets in the valence post-CCSD(T) steps (in W4.3 theory) further increases the $\mathrm{TAE}_{0}$ by a very small amount of $0.02 \mathrm{kcal} / \mathrm{mol}[109]$, and in addition W4.3 includes a $\hat{T}_{6}$ contribution of $0.05 \mathrm{kcal} / \mathrm{mol}$. Thus, the discrepancy between W4.3 and ATcT is reduced to merely $0.07 \mathrm{kcal} / \mathrm{mol}$. However, the other four systems with large discrepancies (formic acid, trans/cis-nitrous acid, and propane) are characterized by mild to moderate nondynamical correlation effects (e.g., $\% \operatorname{TAE}_{e}[(\mathrm{~T})]=1.0-5.4 \%$ ). The lion's share of the discrepancy between theory and experiment can, by default, be attributed to deficiencies in the theoretical ZPVE.

What about the reduced-cost members of the Wn family? Estimating the post-CCSD(T) corrections from a computationally relatively inexpensive CCSDT(Q)/PVDZ calculation, as is done in the W4lite protocol, results in $\mathrm{RMSD}=0.125$ and MAD $=0.093 \mathrm{kcal} / \mathrm{mol}$ over the set of 35 highly accurate ATcT values. (We note that the (Q) step, which dominates the 
cost, parallelizes exceedingly well.) Again, these statistics are in close agreement with the error statistics obtained in ref.[24] $(\mathrm{RMSD}=0.12$ and $\mathrm{MAD}=0.09 \mathrm{kcal} / \mathrm{mol})$. Additionally, downgrading the basis sets used for the SCF, CCSD, and (T) extrapolations (i.e., the W3.2 protocol) results in another deterioration in the error statistics, namely, RMSD $=0.192$ and $\mathrm{MAD}=0.143 \mathrm{kcal} / \mathrm{mol}$ (the corresponding values from ref.[24] are 0.16 and $0.12 \mathrm{kcal} / \mathrm{mol}$, respectively). Removing the post-CCSD(T) contributions from W3.2 theory altogether (i.e., W2.2 theory) significantly degrades performance $(\mathrm{RMSD}=0.743$ and $\mathrm{MAD}=0.414$ $\mathrm{kcal} / \mathrm{mol}$ ); note also that the atomization energies are now on average underestimated - as indicated by an MSD of $-0.368 \mathrm{kcal} / \mathrm{mol}$ - as well as that MAD/RMSD is far removed from the idealized $\approx 4 / 5$ value. However, it should be mentioned that omitting the ten systems for which $\% \operatorname{TAE}_{e}[(\mathrm{~T})] \geq 5 \%$ from the evaluation set reduces the W2.2 error statistics to: RMSD $=0.251, \mathrm{MAD}=0.182$, and $\mathrm{MSD}=-0.118 \mathrm{kcal} / \mathrm{mol}$. Thus, for systems dominated by mild nondynamical correlation effects (i.e., for which $\% \operatorname{TAE}_{e}[(\mathrm{~T})] \leq 5 \%$ ) W2.2 theory (like the original W2[98]) affords a respectable 95\% confidence interval of about half a $\mathrm{kcal} / \mathrm{mol}$. (This illustrates, by the way, the usefulness of the MAD/RMSD ratio as a convenient probe for outliers.)

The above error statistics imply $95 \%$ confidence intervals for the $\mathrm{W} n$ methods of about 1.49 (W2.2), 0.38 (W3.2), 0.25 (W4lite), and $0.17 \mathrm{kcal} / \mathrm{mol}$ (W4). Figure 1 shows the normal distribution functions for the errors between the theoretical and experimental atomization energies. It illustrates that, in order to consistently obtain atomization energies with benchmark (or better) accuracy, post-CCSD(T) contributions of at least up to CCSDT(Q) must be included. In a recent publication, we have shown that post-CCSD $(\mathrm{T})$ correlation effects, in particular, connected quadruple excitations, are essential for obtaining $r_{e}$ and $\omega_{e}$ with RMSD from experiment of $0.0005 \AA$ and $2 \mathrm{~cm}^{-1}$, respectively[109].

\section{The W4-11 dataset and subsets thereof}

Table SI-IV of the Supporting Information contains the final 140 atomization energies of the entire W4-11 dataset calculated at the W4 (or higher) level (this set is denoted TAE140). Two values are listed: (a) zero-point exclusive, non-relativistic, clamped-nuclei TAEs for validation/parametrization of DFT functionals, and (b) zero-point inclusive, relativistic TAEs with DBOC for comparison with experiment. 
For the purpose of testing and/or parametrizing DFT functionals, the TAE140 test set can be divided into two subsets:

(a) A non-multireference (TAE_nonMR124) subset of 124 systems, for which the $\% \operatorname{TAE}_{e}[(\mathrm{~T})]$ diagnostic is below $10 \%$

(b) A multireference (TAE_MR16) subset of 16 systems, for which the $\% \mathrm{TAE}_{e}[(\mathrm{~T})]$ diagnostic is in excess of $10 \%$, namely, $\mathrm{Be}_{2}, \mathrm{~B}_{2}, \mathrm{C}_{2}\left({ }^{1} \Sigma^{+}\right), \mathrm{BN}\left({ }^{1} \Sigma^{+}\right)$, OF, $\mathrm{F}_{2} \mathrm{O}, \mathrm{FOO}$, FOOF, $\mathrm{Cl}_{2} \mathrm{O}, \mathrm{ClOO}, \mathrm{OClO}, \mathrm{O}_{3}, \mathrm{~S}_{3}$, and $\mathrm{S}_{4}$ (note that cis/trans- $\mathrm{HO}_{3}$ for which $\% \mathrm{TAE}_{e}[(\mathrm{~T})]=7.4$ and 7.9 , respectively, are also included in this subset).

These two subsets are given in Table SI-V of the Supporting Information. In the following Section, we compare the relative performance of different DFT exchange-correlation functionals in predicting the atomization reaction energies.

The TAE140 test set of 140 atomization reactions proves to be very challenging for DFT functionals (in particular the TAE_MR14 subset is extremely taxing), and thus serves as a critical test case for any DFT method. However, we acknowledge that DFT and composite thermochemical procedures are often used for computing energies of reactions that are less demanding from the electronic structure point of view (e.g., isomerization and bond dissociation reactions) due to a larger degree of systematic error cancelation between reactants and products[110]. We therefore introduce four additional reaction subsets to the W4-11 database: 99 bond dissociation (BDE99), 707 heavy-atom transfer (HAT707), 20 isomerization (ISOMER20), and 13 nucleophilic substitution reactions (SN13). The W4 (or higher) reference reaction energies for these four subsets are depicted in Tables SI-VI-SI-IX of the Supporting Information. Figure 2 shows the reaction energy distribution of the five subsets of the W4-11 database. The reactions in the HAT707 subset are distributed over a symmetric range from -242.7 to $+242.6 \mathrm{kcal} / \mathrm{mol}$ in a smooth sigmoid fashion. All the reaction energies in the other subsets are positive and span the following ranges: 2.7-1007.9 (TAE140), 5.3-237.1 (BDE99), 0.2-132.2 (ISOMER20), and 2.5-48.1 kcal/mol (SN13). 


\section{Performance of density functional theory and composite thermochemical} procedures for the W4-11 database

In the present section, we evaluate the performance of a selected set of 31 DFT exchange-correlation functionals and 7 empirical composite thermochemical procedures and 5 nonempirical thermochemical procedures for the five subsets in the W4-11 database (TAE140, BDE99, HAT707, ISOMER20, and SN13). We point out, however, that the Supporting Information includes a perl script that will automatically generate the error statistics for any given procedure with a push of a button, in addition to the required Gaussian input files.

To ensure we are "comparing apples to apples", so to speak, the reference W4-11 data employed here are the clamped-nuclei, nonrelativistic, zero-point exclusive values. For consistency, data from composite thermochemistry schemes considered were brought on the same footing. The $\operatorname{CCSD}(\mathrm{T}) / \mathrm{cc}-\mathrm{pV}(\mathrm{Q}+\mathrm{d}) \mathrm{Z}$ reference geometries and the reference reaction energies are given as Supporting Information. The root mean square deviations (RMSD), mean signed deviations (MSD), and mean average deviations (MAD) for the subsets of reactions in the W4-11 database are gathered in Tables $\mathrm{VI} \mathrm{X}$.

(The dispute as to which error measure, RMSD or MAD, is the superior one is nearly as old as modern statistics: Huber's textbook on robust statistics[11] quotes Eddington as favoring the more robust MAD[112], and Fisher as favoring RMSD which has an intuitive relationship to measurement error[113]. The MAD/RMSD ratio for a purely Gaussian error distribution with no systematic error was found by Geary[114] to be $\sqrt{2 / \pi} \approx 0.7979 \approx \frac{4}{5}$ : in fact, he proposed[115] the equivalent $d / \sigma$ ratio as a measure for kurtosis, with values below $\sqrt{2 / \pi}$ indicating a leptokurtic (peaked, long tail) distribution, and values above $\sqrt{2 / \pi}$ one that is platykurtic (flattened, short tail). For a general distribution, a didactic article[116] shows that the MAD/RMSD ratio for $N$ observation is bounded from below by $\sqrt{1 / N}$ for a single nonzero error, and by 1 (unity) for homogenous errors $\pm E$. For a Gaussian distribution with random error $\sigma$ and systematic error $a$, the present authors find that

$$
\frac{\mathrm{MAE}}{\mathrm{RMSE}}=\frac{\sqrt{\frac{2}{\pi}} \exp \left(-\frac{1}{2} x^{2}\right)+x \operatorname{erf}\left(\frac{x}{\sqrt{2}}\right)}{\sqrt{1+x^{2}}}
$$

where $x \equiv \frac{a}{\sigma}$. It is easily seen that in the limit for small $\mathrm{x}$, this ratio approaches $\sqrt{2} \pi$, while in the limit for large $x$, it approaches unity. Note that even for $a=\sigma$, the ratio only reaches 
0.82493 , so $\sqrt{2 / \pi}$ or $4 / 5$ is still a good rule of thumb. Ratios well below that, in the present context, typically indicate one or more large outliers.)

Performance of the various functionals for the 140 atomization reactions are summarized in Table VI. Beginning with the subset of 124 non-multireference systems (for which the $\% \operatorname{TAE}_{e}[(\mathrm{~T})]<10 \%$, TAE_nonMR124). Not surprisingly, LDA overbinds strongly. The only GGA or meta-GGA that has an RMSD below $5 \mathrm{kcal} / \mathrm{mol}$ are B97-D and $\tau$-HCTH (at 4.3 and $4.7 \mathrm{kcal} / \mathrm{mol}$, respectively), which is followed by M06-L (5.3 kcal/mol); PBE's conspicuously high RMSD (16.9 kcal/mol) is largely due to systematic overbinding. Among conventional hybrid GGAs and meta-GGAs, PW6B95 emerges as the best performer with RMSD=2.5 $\mathrm{kcal} / \mathrm{mol}$. While it (like B1B95) is technically a meta-GGA in the correlation functional owing to the kinetic energy density-dependent factor that suppresses self-correlation, it is a simple GGA otherwise. The fact that it, with a mere six empirical parameters, manages to outperform vastly more complex hybrid meta-GGAs like M06 and M06-2X is intriguing. For the W4-11 dataset, PW6B95 represents a significant, but not spectacular, improvement over the related B1B95 functional; both are trailed at some distance by the hybrid GGAs B3PW91 (3.7), PBE0 (4.1), and B3LYP (4.3 kcal/mol). "True" hybrid meta-GGAs considered (except for M06-HF and TPSSh) exhibit RMSDs ranging between 2.8-3.9 kcal/mol, with BMK and M06-2X emerging as the best performers. (We also note in passing that, among 'pure' hybrid GGAs, B3PW91 appears to edge out the others, including B3LYP.) The range-separated hybrid $\omega$ B97-X slightly bests PW6B95 at $2.4 \mathrm{kcal} / \mathrm{mol}$ - and also outperforms it for the DBH24 set of barrier heights — while $\omega$ B97, which has no Hartree-Fock exchange in the short-range part, still achieves a respectable $3.1 \mathrm{kcal} / \mathrm{mol}$. Finally, the double hybrids, as a group, show the best overall performance with RMSDs varying between $1.8-2.7 \mathrm{kcal} / \mathrm{mol}$. In particular, ROB2-PLYP and B2GP-PLYP yield RMSD below $2.0 \mathrm{kcal} / \mathrm{mol}$. If performance for reaction barrier heights is also a consideration, then DSD-BLYP, B2GP-PLYP, and ROB2-PLYP have the edge over the others.

The composite wavefunction-based thermochemical procedures (G3B3, G3(MP2)B3, G4, G4(MP2), CBS-QB3, and ROCBS-QB3) perform rather well with RMSDs of 1.8-2.0 kcal/mol. However, the recently developed G4(MP2)-6X procedure performs exceptionally well with an RMSD of only $1.1 \mathrm{kcal} / \mathrm{mol}$. The nonempirical W1-type procedures attain sub-kcal/mol RMSDs of 0.57-0.69 kcal/mol (with W1U, surprisingly, performing marginally better than W1Usc and W1RO), while ccCA and ccCA-PS3 procedures afford RMSDs of 1.08 
and $1.03 \mathrm{kcal} / \mathrm{mol}$, respectively. We do note that ccCA and ccCA-PS3 are computationally more affordable than the W1 procedures, as their basis set extrapolation steps take place at the MP2 rather than the CCSD or $\operatorname{CCSD}(\mathrm{T})$ level; in addition, a resolution of the identity (RI-MP2) approximation[117] can be applied to said MP2 steps[118], further reducing CPU time and (drastically so) disk space requirements, and leaving $\operatorname{CCSD}(\mathrm{T}) /$ aug-cc-pV $(\mathrm{T}+\mathrm{d}) \mathrm{Z}$ as the most time-consuming step. ccCA may be seen as intermediate, in quality and computational cost, between W1 and the Gn family, but devoid of the latter's empiricism. Note that the MAD/RMSD ratio for ccCA is considerably less than the value for a normal distribution, and detailed inspection indeed reveals errors of $2.5-5 \mathrm{kcal} / \mathrm{mol}$ for several molecules $\left(\mathrm{AlCl}_{3}, \mathrm{AlF}_{3}, \mathrm{~S}_{2} \mathrm{O}, \mathrm{SO}_{2}, \mathrm{SiF}_{4}\right.$, and $\mathrm{SO}_{3}$, in increasing order of error), all of which have second-row atoms in high oxidation states. As discussed at length in Ref. [87], in such molecules the second-row $3 d$ orbital is low enough in energy that it will accept back-bonding from $\mathrm{O}$ and $\mathrm{F}$ lone pairs, making the $3 d$ an 'honorary valence orbital', and a good description of its high-exponent region is imperative. W1 theory adds two tight $d$ functions and a tight $f$ function to every 2nd-row atom in all basis set extrapolation steps, while W2, W3, and W4 go out to mich larger basis sets to begin with.

Inclusion of the 16 highly multireference systems (with $\% \operatorname{TAE}_{e}[(\mathrm{~T})]>10 \%$ ) has a pronounced effect on the error statistics of some of the functionals, particularly those that involve a high fraction of exact exchange. Specifically, upon inclusion of the 16 systems the RMSDs are increased by as much as 4.1 (M06-HF), 3.1 (BH\&HLYP), 2.9 ( $\omega$ B97), 2.7 ( $\omega$ B97$\mathrm{X}), 2.0(\mathrm{BMK})$, and $1.9 \mathrm{kcal} / \mathrm{mol}(\mathrm{M} 06-2 \mathrm{X})$. At the other extreme, the RMSDs of M06L, TPSSh, M06, DSD-BLYP, and B2-PLYP are increased by only 0.1-0.5 kcal/mol. Again, the double hybrids emerge as the best performers for the entire set of 140 atomization energies (TAE140). Among them, B2-PLYP and DSD-BLYP are the most resilient toward strong nondynamical correlation: if performance on barrier heights is also a consideration, then DSD-BLYP emerges as the winner. Finally, we note that the performance statistics of the empirical composite $a b$ initio procedures are not significantly affected by the inclusion of the 16 highly multireference systems. As expected, the performance of the nonempirical W1type procedures (that do not account for explicit or implicit post-CCSD $(\mathrm{T})$ contributions) deteriorates upon inclusion of the highly multireference systems, namely, the RMSD are: 0.9 (W1U), 1.1 (W1Usc), and $0.9 \mathrm{kcal} / \mathrm{mol}$ (W1RO).

Table VII gives the error statistics over the BDE99 subset of 99 bond dissociation 
reactions. The GGAs and meta-GGAs show relatively poor performance with RMSDs varying between 4.7 (B97-D) and $10.0 \mathrm{kcal} / \mathrm{mol}$ (PBE). The hybrid GGAs (except for BH\&HLYP) attain RMSDs between 3.2-5.4 kcal/mol, where B97-1 (and, to a lesser extent, PW6B95) perform significantly better than the rest. The hybrid meta-GGAs (other than M06-HF) show similar performance for BDE99: RMSDs vary between 3.7-5.1 kcal/mol, with M06 putting in the best performance. Overall, the double hybrids give the best performance with RMSDs varying between 2.5-3.3 kcal/mol (excluding B2K-PLYP, which was parametrized for thermochemical kinetics and attains an RMSD of $4.1 \mathrm{kcal} / \mathrm{mol}$ ). In particular, we note the good performance of ROB2-PLYP and B2-PLYP with an RMSD of $2.5 \mathrm{kcal} / \mathrm{mol}$. The empirical composite ab initio procedures yield RMSDs ranging between 1.0-1.9 $\mathrm{kcal} / \mathrm{mol}$, where G4 and G4(MP2) offer up the best performance with RMSDs of 1.0 and $1.1 \mathrm{kcal} / \mathrm{mol}$, respectively. Of the W1-type procedures, W1RO $(\mathrm{RMSD}=$ $0.8 \mathrm{kcal} / \mathrm{mol}$ ) performs significantly better than W1U and W1Usc (RMSD $=1.2$ and 1.4 $\mathrm{kcal} / \mathrm{mol}$, respectively). The ccCA and ccCA-PS3 methods exhibit similar performance as W1RO, with an RMSD of $0.8 \mathrm{kcal} / \mathrm{mol}$.

The error statistics for the HAT707 subset of 707 heavy-atom transfer reaction energies are summarized in Table VIII. The RMSDs for the GGAs and meta-GGAs vary between $5.3(\mathrm{M} 06-\mathrm{L})$ and $8.0 \mathrm{kcal} / \mathrm{mol}(\mathrm{PBE})$. The hybrid GGAs (excluding BH\&HLYP) perform acceptably well with RMSDs ranging between 3.6-5.1 kcal/mol, PW6B95 displaying the best performance, closely followed by B97-1. Similarly, the hybrid meta-GGAs (excluding M06-HF) attain RMSDs varying between 3.9-5.5 kcal/mol, B1B95 performing the best. All the double hybrids show very good performance with RMSDs varying between 2.3-3.1 $\mathrm{kcal} / \mathrm{mol}$ (aside from B2K-PLYP which gives an RMSD of $4.1 \mathrm{kcal} / \mathrm{mol}$ ). Of the empirical composite thermochemical procedures, G4 gives the best performance with a RMSD of 1.2 $\mathrm{kcal} / \mathrm{mol}$, while ccCA, ccCA-PS3, and W1RO emerge as the best nonempirical procedures with RMSDs of 1.0-1.3 kcal/mol.

Figure 3 shows the RMSDs of the exchange-correlation functionals and composite thermochemical procedures over the TAE140, BDE99, and HAT707 subsets of the W4-11 database.

Turning our attention to the much smaller ISOMER20 subset of 20 isomerization reactions present in the W4-11 dataset (Table IX), we note that almost all of the functionals considered perform well. Most notably, all of the considered hybrid GGAs (except for BH\&HLYP), 
hybrid meta-GGAs (excluding M06-HF and TPSSh), and double hybrids (excluding B2KPLYP) give RMSDs between 2.0-3.0 kcal/mol. In particular, we note that M06-2X gives an RMSD of only $1.5 \mathrm{kcal} / \mathrm{mol}$ for this subset. As expected, the composite thermochemical procedures perform especially well for the isomerization energies, with RMSD below the "chemical accuracy" threshold of $1 \mathrm{kcal} / \mathrm{mol}$. Most notably, G3B3, G3(MP2)B3, CBS-QB3, ROCBS-QB3, ccCA, and ccCA-PS3 attain RMSDs between $0.3-0.5 \mathrm{kcal} / \mathrm{mol}$, whereas the W1-type procedures attain RMSDs of $0.2 \mathrm{kcal} / \mathrm{mol}$.

Likewise, for the SN13 subset of 13 nucleophilic substitution reactions present in the W4-11 dataset (Table $\mathrm{X}$ ), nearly all of the functionals show excellent performance. In particular, the GGA (M06-L), the hybrid GGAs ( $\omega$ B97-X, $\omega$ B97, PBE0, and B3PW91), the hybrid meta-GGAs (BMK, M06-2X, and B1B95) attain RMSDs of 1.0-1.4 kcal/mol. The double hybrids (excluding B2-PLYP) attain RMSDs lower than $1.0 \mathrm{kcal} / \mathrm{mol}$, most notably: B2K-PLYP (0.4), B2GP-PLYP (0.7), and ROB2-PLYP (0.7 kcal/mol). The same is true for the composite thermochemical procedures, where the CBS-QB3, ROCBS-QB3, ccCA-type, and W1-type procedures all attain RMSDs of $0.3 \mathrm{kcal} / \mathrm{mol}$.

\section{CONCLUSIONS}

This work provides an extension to the W4-08 dataset to be known as the W4-11 dataset. The W4-11 dataset is aimed for testing/parametrizing approximate electronic structure methods such as DFT functionals. The W4-11 dataset includes a total of 140 highly accurate atomization energies obtained by means of the W4 (or higher) thermochemical protocol. Of these 140 atomization energies, 35 highly accurate experimental values (with associated uncertainty of $\pm 0.05 \mathrm{kcal} / \mathrm{mol}$, or narrower) are available from ATcT. Against these 35 data points W4 theory affords a root mean square deviation of $0.085 \mathrm{kcal} / \mathrm{mol}$, a mean absolute deviation of $0.065 \mathrm{kcal} / \mathrm{mol}$ (implying a $95 \%$ confidence interval of about $0.17 \mathrm{kcal} / \mathrm{mol}$ ). For the lower-cost members of the Wn family, the following RMSDs (and 95\% confidence interval in parentheses) are obtained: $0.13(0.25)$ W4lite, 0.19 (0.38) W3.2, and $0.74(1.49 \mathrm{kcal} / \mathrm{mol})$ W2.2. We note that the RMSD for W2.2 theory drops to $0.25 \mathrm{kcal} / \mathrm{mol}$ (implying a $95 \%$ confidence interval of about $0.50 \mathrm{kcal} / \mathrm{mol}$ ) after eliminating the ten systems dominated by moderate or severe nondynamical correlation effects (i.e., with $\% \mathrm{TAE}_{e}[(\mathrm{~T})]$ diagnostic $\geq$ $5 \%$ ) from the evaluation set. The MAD/RMSD ratio, which is nearly the idealized $\approx 4 / 5$ 
value for W4 but considerably lower for W2.2, likewise indicates outlier issues with W2.2.

A plethora of energetic data can be generated from the 140 atomizations energies in the W4-11 dataset. In particular, the following subsets of reactions are introduced: 99 bond dissociation (BDE99), 707 heavy-atom transfer (HAT707), 20 isomerization (ISOMER20), and 13 nucleophilic substitution reactions (SN13).

Finally, the performance of 30 commonly used DFT functionals over the subsets in the W4-11 database is evaluated. The following general observations are offered: (a) the GGA and meta-GGAs show poorer performance than the hybrid and double-hybrid functionals, with B97-D and M06L putting in the best performances; (b) among hybrid GGAs and meta-GGAs, PW6B95 is the best performer, followed by M06-2X, BMK, and B1B95, with PW6B95 and B1B95 being more resilient toward nondynamical correlation than the two others, and M06-2X offering superlative performance for barrier heights; (c) range-separated hybrid GGAs outperform both conventional hybrid GGAs and ditto meta-GGAs, but appear to be hypersensitive toward nondynamical correlation; (d) among double hybrids, B2GPPLYP, ROB2-PLYP and DSD-BLYP all perform at accuracies comparable to composite ab initio methods like G3 theory. The spin-component scaled double hybrid DSD-BLYP has an edge over the other functionals in terms of resilience toward nondynamical correlation; (e) among the composite ab initio thermochemistry methods, only W1 theory breaks the 1 $\mathrm{kcal} / \mathrm{mol}$ barrier for RMSD values, but the very recent G4(MP2)-6X method of Radom and coworkers offers a stellar price-performance ratio.

\section{Acknowledgments}

JMLM is on leave of absence as the Thatcher Professor of Chemistry at the Weizmann Institute of Science. This research was supported in part by the Weizmann AERI (Alternative Energy Research Initiative). AK was supported by Australian Research Council Discovery Project grant DP110102336. The authors would like to acknowledge a generous grant of computer time by the Faculty of Chemistry at the Weizmann Institute of Science. 


\section{Supporting Information}

Diagnostics for the importance of nondynamical correlation effects for the entire W4-11 dataset are presented in Table SI-I. The component breakdown of the final atomization energies at the bottom of the well for the entire W4-11 data set are presented in Table SI-II. Table SI-III compares the final W2.2, W3.2, W4lite, and W4 total atomization energies at $0 \mathrm{~K}$ with experimental determinations from Active Thermochemical Tables (ATcT). Table SI-IV presents the final W4-11 dataset of 140 total atomization energies of the TAE140 subset. In Table SI-V the 140 total atomization energies are divided into subsets according to multireference considerations (i.e., gives the TAE_nonMR126 and TAE_MR14 subsets). Table SI-VI presents the 99 bond dissociation energies of the BDE99 subset. Table SIVII presents the 707 heavy-atom transfer reaction energies of the HAT707 subset. Table SI-VIII presents the 20 isomerization reaction energies of the ISOMER20 subset. Table SIIX presents the 13 nucleophilic substitution reaction energies of the SN13 subset. Finally, the directory named "W4-11-DATABASE" includes a perl script that will automatically generate the error statistics for all or some of these reaction subsets with a push of a button, in addition to the required Gaussian input job files. Note that the reference CCSD(T)/cc$\mathrm{pV}(\mathrm{Q}+\mathrm{d}) \mathrm{Z}$ geometries used in the W4-11 datasets are provided in the Gaussian input files. 
TABLE I: List of the 140 molecules in the W4-11 dataset. ${ }^{a}$

\begin{tabular}{|c|c|c|c|c|c|c|c|c|c|c|c|}
\hline Molecule & Name & Protocol & Molecule & Name & Protocol & Molecule & Name & Protocol & Molecule & Name & Protocol \\
\hline $\mathrm{F}_{2} \mathrm{O}_{2}$ & dioxygen difluoride & W4 & $\mathrm{H}_{2} \mathrm{C}=\mathrm{O}$ & formaldehyde & $\mathrm{W} 4.2$ & HSS. & hydrogen disulfide & W4.2 & $\mathrm{F}_{2} \mathrm{C}:$ & carbon difluoride & W4 \\
\hline $\mathrm{OOCl}$. & dioxygen chloride & W4 & $\mathrm{H}(\mathrm{O}=) \mathrm{C}$. & formyl radical & W4.2 & HоO. & hydroperoxy radical & W4.2 & $\mathrm{H}_{2} \mathrm{C}:{ }^{3} B_{1}$ & methylene & W4.4 \\
\hline OOF. & dioxygen fluoride & W4 & $\mathrm{CS}_{2}$ & carbon disulfide & W4 & $\mathrm{H}_{2} \mathrm{O}$ & water & W4.4 & $\mathrm{H}_{2} \mathrm{C}:{ }^{1} A_{1}$ & methylene $^{b}$ & W4 \\
\hline$[\mathrm{OClO}]$. & chlorine dioxide & W4 & OCS & carbon oxide sulfide & W4 & HO. & hydroxyl radical & W4.4 & FSi. & silicon fluoride & W4.3 \\
\hline $\mathrm{ClOCl}$ & dichlorine monoxide & W4 & $\mathrm{CO}_{2}$ & carbon dioxide & W4.2 & $\mathrm{HN}_{3}$ & hydrogen azide ${ }^{b}$ & W4 & $\mathrm{ClC} \equiv \mathrm{N}$ & cyanogen chloride & W4 \\
\hline FOF & difluorine monoxide & $\mathrm{W} 4.2$ & CS & carbon sulfide & W4.3 & $\mathrm{H}_{4} \mathrm{~N}_{2}$ & hydrazine & W4 & FC. & fluoromethylidyne & $\mathrm{W} 4.2$ \\
\hline $\mathrm{HOCl}$ & hypochlorous acid & $\mathrm{W} 4.2$ & $\mathrm{SiO}$ & silicon monoxide & W4.3 & trans- $\mathrm{H}_{2} \mathrm{~N}_{2}$ & diazene & W4 & HC. & methylidyne & W4.4 \\
\hline $\mathrm{HOF}$ & hypofluorous acid & W4.3 & $\mathrm{CO}$ & carbon monoxide & W4.4 & cis- $\mathrm{H}_{2} \mathrm{~N}_{2}$ & diazene $^{b}$ & W4 & $\mathrm{B}_{2} \mathrm{H}_{6}$ & diborane & W4 \\
\hline $\mathrm{ClO}$. & chlorine monoxide & W4.4 & $\mathrm{H}_{2} \mathrm{~N}-\mathrm{CH}_{2}$ & aminomethyl radical & W4 & $\mathrm{HN} \equiv \mathrm{N}$. & dinitrogen monohydride & $\mathrm{W} 4$ & $\mathrm{BF}_{3}$ & trifluoroborane & W4 \\
\hline FO. & fluorine monoxide & W4.4 & $\mathrm{H}_{3} \mathrm{C}-\mathrm{NH}$. & methylamine radical & W4 & $\mathrm{H}_{2} \mathrm{NCl}$ & chloramine ${ }^{b}$ & W4 & $\mathrm{HBF}_{2}$ & difluoroborane & W4 \\
\hline $\mathrm{O}_{2} \mathrm{~N}$. & nitrogen dioxide & $\mathrm{W} 4.2$ & $\mathrm{CH}_{3} \mathrm{NH}_{2}$ & methylamine & W4 & $\mathrm{NH}_{3}$ & ammonia & W4.4 & BF & boron monofluoride & W4.3 \\
\hline $\mathrm{N}^{-}=\mathrm{N}^{+}=\mathrm{O}$ & nitrous oxide & $\mathrm{W} 4.2$ & $\mathrm{H}_{2} \mathrm{C}=\mathrm{NH}$ & methanimine & $\mathrm{W} 4.2$ & $\mathrm{H}_{2} \mathrm{~N}$. & amino radical & W4.3 & $\mathrm{BN}^{3} \Pi$ & boron nitride & W4.2 \\
\hline trans- $\mathrm{HON}=\mathrm{O}$ & nitrous acid ${ }^{b}$ & W4 & $\mathrm{H}_{2} \mathrm{C}=\mathrm{N}$. & methanimine radical & W4 & HN & imidogen radical & W4.3 & $\mathrm{BN}^{1} \Sigma^{+}$ & boron nitride & W4.3 \\
\hline cis- $\mathrm{HON}=\mathrm{O}$ & nitrous acid ${ }^{b}$ & W4 & $\mathrm{HN}=\mathrm{CH}$. & iminometyl radical $^{b}$ & W4 & $\mathrm{C}_{3} \mathrm{H}_{4}$ & allene $^{c}$ & W4h & $\mathrm{H}_{3} \mathrm{~B}$ & borane & W4.3 \\
\hline HNC: & hydrogen isocyanide ${ }^{b}$ & W4 & $\mathrm{HCN}$ & hydrogen cyanide & W 4.3 & $\mathrm{C}_{3} \mathrm{H}_{4}$ & propyne $^{c}$ & W4h & HB & boron monohydride & W4.3 \\
\hline $\mathrm{HOCN}$ & cyanic acid ${ }^{b}$ & W4 & $\mathrm{N} \equiv \mathrm{C}-\mathrm{C} \equiv \mathrm{N}$ & cyanogen & W4 & $\mathrm{C}_{3} \mathrm{H}_{6}$ & propene $^{c}$ & W4h & $\mathrm{BeF}_{2}$ & beryllium fluoride & $\mathrm{W} 4.2$ \\
\hline HONC: & isofulminic $\operatorname{acid}^{b}$ & W4 & $\mathrm{N} \equiv \mathrm{C}$. & cyano radical & W4.4 & $\mathrm{C}_{3} \mathrm{H}_{8}$ & propane $^{c}$ & W4h & $\mathrm{BeCl}_{2}$ & beryllium chloride & W4 \\
\hline $\mathrm{HNCO}$ & isocyanic acid ${ }^{b}$ & W4 & $\mathrm{HCl}$ & hydrogen chloride & W4.4 & $\mathrm{C}_{2} \mathrm{H}_{5} \mathrm{~F}$ & fluoroethane $^{b}$ & W4 & $\mathrm{Be}_{2}$ & diberyllium & W4.3 \\
\hline HCNO & formonitrile oxide ${ }^{b}$ & W4 & $\mathrm{H}_{2} \mathrm{~S}$ & hydrogen sulfide & W4.4 & $\mathrm{C}_{2} \mathrm{H}_{6}$ & ethane & W4 & SSO & disulfur oxide & W4 \\
\hline $\mathrm{HN}=\mathrm{O}$ & nitrosyl hydride & $\mathrm{W} 4.2$ & HS. & mercapto radical & W4.4 & $\mathrm{C}_{2} \mathrm{H}_{3} \mathrm{~F}$ & fluoroethylene ${ }^{b}$ & W4 & $\mathrm{SO}_{3}$ & sulfur trioxide & W4 \\
\hline ON. & nitric oxide & W4.4 & $\mathrm{H}_{3} \mathrm{P}$ & phosphine & W4.4 & $\mathrm{C}_{2} \mathrm{H}_{4}$ & ethene & W4.2 & $\mathrm{SO}_{2}$ & sulfur dioxide & W4 \\
\hline $\mathrm{H}_{2} \mathrm{C}_{2} \mathrm{O}$ & oxirene $^{b}$ & W4 & $\mathrm{Si}_{2} \mathrm{H}_{6}$ & disilane & W4 & $\mathrm{H}_{2} \mathrm{C}=\mathrm{CH}$. & vinyl radical & $\mathrm{W} 4.2$ & SO & sulfur monoxide & W4.4 \\
\hline $\mathrm{C}_{2} \mathrm{H}_{4} \mathrm{O}$ & oxirane $^{b}$ & W4 & $\mathrm{SiH}_{4}$ & silane & W4.3 & $\mathrm{H}_{2} \mathrm{C}=\mathrm{C}:$ & vinylidene & W4.2 & $\mathrm{S}_{4}$ & tetrasulfur & W4 \\
\hline $\mathrm{H}_{2} \mathrm{CO}_{2}$ & dioxirane $^{b}$ & W4 & $\mathrm{HSi}$. & silicon hydride & $\mathrm{W} 4.3$ & $\mathrm{FC} \equiv \mathrm{CF}$ & difluoroacetylene ${ }^{b}$ & W4 & $\mathrm{S}_{3}$ & trisulfur & W4 \\
\hline $\mathrm{C}_{2} \mathrm{H}_{5} \mathrm{OH}$ & ethanol $^{b}$ & W4 & $\mathrm{AlCl}_{3}$ & aluminum chloride & W4 & $\mathrm{HC} \equiv \mathrm{CF}$ & fluoroacetylene ${ }^{b}$ & W4 & $\mathrm{S}_{2}$ & disulfur & W4.4 \\
\hline $\mathrm{CH}_{3} \mathrm{OH}$ & methanol $^{b}$ & $\mathrm{~W} 4$ & $\mathrm{AlF}_{3}$ & aluminum fluoride & W4 & $\mathrm{HC} \equiv \mathrm{CH}$ & acetylene & W4.4 & $\mathrm{P}_{4}$ & tetraphosphorus & W4 \\
\hline trans-H(HO)C: & hydroxymethylene $^{b}$ & W4 & $\mathrm{AlH}_{3}$ & aluminum trihydride & $\mathrm{W} 4.3$ & $\mathrm{HC} \equiv \mathrm{C}$. & ethynyl radical & W4.4 & $\mathrm{P}_{2}$ & diphosphorus & W4.4 \\
\hline cis- $\mathrm{H}(\mathrm{HO}) \mathrm{C}$ : & hydroxymethylene ${ }^{b}$ & $\mathrm{~W} 4$ & $\mathrm{AlCl}$ & aluminum monochloride & $\mathrm{W} 4.3$ & $\mathrm{SiF}_{4}$ & tetrafluorosilane ${ }^{b}$ & W4 & $\mathrm{Cl}_{2}$ & dichlorine & W4.4 \\
\hline $\mathrm{HC}(=\mathrm{O}) \mathrm{OH}$ & formic $\operatorname{acid}^{b}$ & W4 & AlF & aluminum monofluoride & $\mathrm{W} 4.3$ & $\mathrm{SiH}_{3} \mathrm{~F}$ & fluorosilane $^{b}$ & W4 & $\mathrm{ClF}$ & chlorine monofluoride & W4.4 \\
\hline $\mathrm{CH}_{3} \mathrm{C}(=\mathrm{O}) \mathrm{OH}$ & acetic $\operatorname{acid}^{b}$ & W4 & $\mathrm{AlH}$ & aluminum hydride & $\mathrm{W} 4.3$ & $\mathrm{CF}_{4}$ & tetrafluoromethane ${ }^{b}$ & W4 & $\mathrm{F}_{2}$ & difluoride & W4.4 \\
\hline $\mathrm{H}_{2} \mathrm{C}=\mathrm{C}=\mathrm{O}$ & ketene $^{b}$ & W4 & HF & hydrogen fluoride & W4.4 & $\mathrm{CH}_{2} \mathrm{~F}_{2}$ & difluoromethane ${ }^{b}$ & W4 & $\mathrm{O}_{2}$ & dioxygen & W4.4 \\
\hline $\mathrm{H}(\mathrm{O}=) \mathrm{C}-\mathrm{C}(=\mathrm{O}) \mathrm{H}$ & glyoxal $^{b}$ & W4 & trans- $\mathrm{HO}_{3}$ & hydrotrioxy radical $^{b}$ & W4 & $\mathrm{CH}_{3} \mathrm{~F}$ & fluoromethane $e^{b}$ & W4 & $\mathrm{N}_{2}$ & dinitrogen & W4.4 \\
\hline $\mathrm{H}_{3} \mathrm{C}-\mathrm{C}(=\mathrm{O}) \mathrm{H}$ & acetaldehyde $^{b}$ & W4 & cis- $\mathrm{HO}_{3}$. & hydrotrioxy radical ${ }^{b}$ & W4 & $\mathrm{CH}_{4}$ & methane & W4.4 & $\mathrm{C}_{2}$ & dicarbon & W4.4 \\
\hline $\mathrm{F}_{2} \mathrm{C}=\mathrm{O}$ & carbonyl fluoride ${ }^{b}$ & W4 & $\mathrm{O}_{3}$ & ozone & $\mathrm{W} 4.2$ & $\mathrm{H}_{3} \mathrm{C}$. & methyl radical & W4.4 & $\mathrm{B}_{2}$ & diboron & W4.3 \\
\hline $\mathrm{HC}(=\mathrm{O}) \mathrm{F}$ & formylfluoride $^{b}$ & W4 & $\mathrm{H}_{2} \mathrm{O}_{2}$ & hydrogen peroxide & $\mathrm{W} 4.2$ & $\mathrm{Cl}_{2} \mathrm{C}$ : & carbon dichloride & W4 & $\mathrm{H}_{2}$ & dihydrogen & W4.4 \\
\hline
\end{tabular}

${ }^{a} \mathrm{~A} \operatorname{dot}(\cdot)$ indicates a radical species, and a colon (:) indicates a carbene.

${ }^{b} 37$ molecules added in the present work.

${ }^{c} 4$ molecules from ref. 43 . 
TABLE II: Diagnostics for importance of nondynamical correlation for the 37 species added to the W4-11 dataset in the present work, as well as squared correlation correlation coefficients $\left(\mathrm{R}^{2}\right)$ between the various diagnostics and the $\% \mathrm{TAE}_{e}[\operatorname{post}-\mathrm{CCSD}(\mathrm{T})]$ and $\% \mathrm{TAE}_{e}\left[T_{4}+T_{5}\right]$ diagnostics over the entire W4-11 dataset.

\begin{tabular}{|c|c|c|c|c|c|c|c|}
\hline & & $\begin{array}{c}\% \mathrm{TAE}_{e} \\
{[\mathrm{SCF}]^{b}}\end{array}$ & $\begin{array}{c}\% \mathrm{TAE}_{e} \\
{[(\mathrm{~T})]^{b}}\end{array}$ & $a, b$ & $\begin{array}{c}\% \mathrm{TAE}_{e} \\
{\left[T_{4}+T_{5}\right]^{b}}\end{array}$ & $\begin{array}{c}\mathcal{T}_{1} \\
\text { diagno }\end{array}$ & $\begin{array}{c}D_{1} \\
\text { ostics }^{c}\end{array}$ \\
\hline $\mathrm{SiH}_{3} \mathrm{~F}$ & fluorosilane & 79.0 & 0.8 & -0.07 & 0.03 & 0.011 & 0.022 \\
\hline $\mathrm{H}_{2} \mathrm{C}:\left({ }^{1} A_{1}\right)$ & methylene & 71.8 & 1.0 & 0.18 & 0.07 & 0.009 & 0.019 \\
\hline $\mathrm{C}_{2} \mathrm{H}_{5} \mathrm{~F}$ & fluoroethane & 76.7 & 1.2 & -0.02 & 0.05 & 0.009 & 0.023 \\
\hline $\mathrm{CH}_{3} \mathrm{OH}$ & methanol & 73.6 & 1.3 & -0.02 & 0.06 & 0.008 & 0.017 \\
\hline $\mathrm{C}_{2} \mathrm{H}_{5} \mathrm{OH}$ & ethanol & 75.1 & 1.3 & -0.03 & 0.06 & 0.009 & 0.019 \\
\hline $\mathrm{CH}_{3} \mathrm{~F}$ & fluoromethane & 75.8 & 1.3 & -0.02 & 0.05 & 0.009 & 0.021 \\
\hline $\mathrm{H}_{3} \mathrm{C}-\mathrm{C}(=\mathrm{O}) \mathrm{H}$ & acetaldehyde & 74.3 & 1.7 & -0.01 & 0.11 & 0.014 & 0.048 \\
\hline $\mathrm{C}_{2} \mathrm{H}_{4} \mathrm{O}$ & oxirane & 72.6 & 1.8 & -0.03 & 0.11 & 0.011 & 0.024 \\
\hline $\mathrm{CH}_{2} \mathrm{~F}_{2}$ & difluoromethane & 73.1 & 1.8 & -0.04 & 0.08 & 0.011 & 0.028 \\
\hline $\mathrm{SiF}_{4}$ & tetrafluorosilane & 77.7 & 1.8 & -0.12 & 0.08 & 0.011 & 0.022 \\
\hline $\mathrm{C}_{2} \mathrm{H}_{3} \mathrm{~F}$ & fluoroethylene & 74.9 & 1.8 & -0.01 & 0.11 & 0.012 & 0.030 \\
\hline $\mathrm{CH}_{3} \mathrm{C}(=\mathrm{O}) \mathrm{OH}$ & acetic acid & 72.3 & 2.0 & -0.01 & 0.13 & 0.015 & 0.054 \\
\hline trans- $\mathrm{H}(\mathrm{HO}) \mathrm{C}$ : & hydroxymethylene & 67.5 & 2.3 & 0.05 & 0.14 & 0.018 & 0.056 \\
\hline cis-H(HO)C: & hydroxymethylene & 66.9 & 2.3 & 0.05 & 0.14 & 0.018 & 0.057 \\
\hline $\mathrm{H}_{2} \mathrm{C}=\mathrm{C}=\mathrm{O}$ & ketene & 71.9 & 2.5 & 0.02 & 0.18 & 0.017 & 0.046 \\
\hline $\mathrm{HC}(=\mathrm{O}) \mathrm{OH}$ & formic acid & 68.6 & 2.5 & -0.01 & 0.17 & 0.016 & 0.052 \\
\hline $\mathrm{HN}=\mathrm{HC}$. & iminometyl radical & 65.7 & 2.6 & 0.08 & 0.2 & 0.028 & 0.083 \\
\hline $\mathrm{H}(\mathrm{O}=) \mathrm{C}-\mathrm{C}(=\mathrm{O}) \mathrm{H}$ & glyoxal & 69.0 & 2.7 & 0.03 & 0.22 & 0.016 & 0.050 \\
\hline $\mathrm{H}_{2} \mathrm{NCl}$ & chloramine & 59.8 & 2.8 & 0.03 & 0.2 & 0.009 & 0.022 \\
\hline $\mathrm{CF}_{4}$ & tetrafluoromethane & 69.2 & 2.8 & -0.08 & 0.13 & 0.011 & 0.030 \\
\hline $\mathrm{HC} \equiv \mathrm{CF}$ & fluoroacetylene & 69.8 & 2.8 & 0.00 & 0.23 & 0.013 & 0.027 \\
\hline $\mathrm{HC}(=\mathrm{O}) \mathrm{F}$ & formylfluoride & 68.8 & 2.8 & -0.01 & 0.18 & 0.01 & 0.031 \\
\hline $\mathrm{HNC}:$ & hydrogen isocyanide & 65.6 & 3.0 & 0.04 & 0.23 & 0.017 & 0.033 \\
\hline $\mathrm{H}_{2} \mathrm{C}_{2} \mathrm{O}$ & oxirene & 64.7 & 3.2 & 0.02 & 0.28 & 0.013 & 0.032 \\
\hline $\mathrm{F}_{2} \mathrm{C}=\mathrm{O}$ & carbonyl fluoride & 66.7 & 3.2 & -0.04 & 0.2 & 0.014 & 0.049 \\
\hline HOCN & cyanic acid & 62.0 & 3.3 & 0.03 & 0.31 & 0.014 & 0.033 \\
\hline $\mathrm{HNCO}$ & isocyanic acid & 64.3 & 3.4 & 0.03 & 0.26 & 0.018 & 0.051 \\
\hline cis- $\mathrm{H}_{2} \mathrm{~N}_{2}$ & diazene & 51.4 & 3.5 & 0.09 & 0.31 & 0.012 & 0.034 \\
\hline $\mathrm{H}_{2} \mathrm{CO}_{2}$ & dioxirane & 58.6 & 3.6 & 0.07 & 0.36 & 0.014 & 0.036 \\
\hline $\mathrm{FC} \equiv \mathrm{CF}$ & difluoroacetylene & 64.6 & 3.6 & -0.01 & 0.29 & 0.013 & 0.030 \\
\hline HONC: & isofulminic acid & 55.4 & 4.0 & 0.06 & 0.35 & 0.017 & 0.039 \\
\hline $\mathrm{HCNO}$ & formonitrile oxide & 53.3 & 4.8 & 0.11 & 0.5 & 0.021 & 0.053 \\
\hline cis- $\mathrm{HON}=\mathrm{O}$ & nitrous acid & 43.7 & 5.3 & 0.21 & 0.5 & 0.021 & 0.063 \\
\hline trans $-\mathrm{HON}=\mathrm{O}$ & nitrous acid & 43.5 & 5.4 & 0.24 & 0.51 & 0.021 & 0.060 \\
\hline $\mathrm{HN}_{3}$ & hydrogen azide & 40.8 & 5.6 & 0.23 & 0.64 & 0.02 & 0.052 \\
\hline cis- $\mathrm{HO}_{3}$. & hydrotrioxy radical & 26.9 & 7.4 & 0.79 & 0.94 & 0.042 & 0.156 \\
\hline trans- $-\mathrm{HO}_{3}$. & hydrotrioxy radical & 25.1 & 7.9 & 0.99 & 1.08 & 0.042 & 0.146 \\
\hline $\mathrm{R}^{2 d}$ & & 0.58 & 0.59 & 1.00 & 0.67 & 0.34 & 0.36 \\
\hline $\mathrm{R}^{2 e}$ & & 0.80 & 0.94 & 0.67 & 1.00 & 0.38 & 0.33 \\
\hline
\end{tabular}

${ }^{a} \% \mathrm{TAE}_{e}[$ post-CCSD $(\mathrm{T})]$, i.e., $\% \mathrm{TAE}_{e}\left[T_{3}-(\mathrm{T})+T_{4}+T_{5}\right] .{ }^{b}$ Percentages of the total atomization energy relate to non-relativistic, clamped-nuclei, valence CCSDTQ5 values from W4 theory. ${ }^{c}$ From an ROCCSD(T)/cc-pVTZ calculation. ${ }^{d} \mathrm{R}^{2}$ between the $\% \mathrm{TAE}_{e}[$ post-CCSD $(\mathrm{T})]$ diagnostic and the other diagnostics over the entire W4-11 dataset of 139 molecules (excluding $\mathrm{Be}_{2}$, see main text). ${ }^{e} \mathrm{R}^{2}$ between the $\% \mathrm{TAE}_{e}\left[T_{4}+T_{5}\right]$ diagnostic and the other diagnostics over the entire W4-11 dataset of 139 molecules (excluding $\mathrm{Be}_{2}$, see main text). 
TABLE III: Basis set dependence of the $\% \operatorname{TAE}_{e}[(\mathrm{~T})]$ diagnostic (equation 1) for the importance of nondynamical correlation effects for the molecules in the W4-11 dataset.

\begin{tabular}{|c|c|c|c|c|}
\hline & AVDZ & AVTZ & AVQZ & AV5Z \\
\hline $\mathrm{RMSD}^{a}$ & 0.78 & 0.15 & 0.08 & 0.06 \\
\hline $\mathrm{MSD}^{a}$ & -0.64 & -0.11 & -0.04 & -0.01 \\
\hline $\mathrm{MAD}^{a}$ & 0.68 & 0.14 & 0.06 & 0.04 \\
\hline
\end{tabular}

${ }^{a}$ Root mean square deviations (RMSD), mean signed deviations (MSD), and mean absolute deviations (MAD) with respect to basis set limit values from W4 theory over the 138 species in the W4-11 test set, two outliers were excluded from the error statistics (namely, $\mathrm{HC}=\mathrm{NH}$ and $\mathrm{Be}_{2}$ ). 
TABLE IV: Component breakdown of the final W4 total atomization energies at the bottom of the well $\mathrm{TAE}_{e}$ (in $\mathrm{kcal} / \mathrm{mol}$ ).

\begin{tabular}{|c|c|c|c|c|c|c|c|c|c|c|c|c|c|}
\hline & & $\mathrm{SCF}$ & & & valence & & & & relativ. & spin- & DBOC & $\mathrm{M}-\mathrm{A}^{a}$ & $\mathrm{TAE}_{e}$ \\
\hline & & & CCSD & $(\mathrm{T})$ & $\hat{T}_{3}-(\mathrm{T})$ & $\hat{T}_{4}$ & $\hat{T}_{5}$ & shell & & orbit & & & \\
\hline $\mathrm{H}_{2} \mathrm{C}_{2} \mathrm{O}$ & oxirene & 293.68 & 145.48 & 14.37 & -1.17 & 1.19 & 0.09 & 2.39 & -0.46 & -0.39 & 0.11 & 0.07 & 455.33 \\
\hline $\mathrm{C}_{2} \mathrm{H}_{4} \mathrm{O}$ & oxirane & 471.05 & 166.38 & 11.81 & -0.95 & 0.70 & 0.04 & 2.46 & -0.56 & -0.39 & 0.13 & 0.07 & 650.70 \\
\hline $\mathrm{H}_{2} \mathrm{CO}_{2}$ & dioxirane & 239.56 & 154.29 & 14.72 & -1.18 & 1.38 & 0.10 & 1.14 & -0.40 & -0.53 & 0.07 & 0.07 & 409.17 \\
\hline $\mathrm{H}_{2} \mathrm{C}=\mathrm{C}=\mathrm{O}$ & ketene & 381.75 & 135.76 & 13.04 & -0.84 & 0.93 & 0.05 & 2.75 & -0.47 & -0.39 & 0.11 & 0.07 & 532.70 \\
\hline $\mathrm{H}_{3} \mathrm{C}-\mathrm{C}(=\mathrm{O}) \mathrm{H}$ & acetaldehyde & 501.58 & 162.09 & 11.63 & -0.77 & 0.70 & 0.04 & 2.58 & -0.53 & -0.39 & 0.12 & 0.07 & 677.07 \\
\hline $\mathrm{HC}(=\mathrm{O}) \mathrm{OH}$ & formic acid & 343.07 & 144.63 & 12.57 & -0.89 & 0.81 & 0.03 & 1.65 & -0.59 & -0.53 & 0.13 & 0.07 & 500.90 \\
\hline $\mathrm{CH}_{3} \mathrm{C}(=\mathrm{O}) \mathrm{OH}$ & acetic acid & 578.81 & 206.15 & 16.15 & $-1.13^{b}$ & $1.08^{c}$ & $\mathrm{~N} / \mathrm{A}$ & 2.91 & -0.79 & -0.62 & 0.21 & 0.09 & 802.82 \\
\hline $\mathrm{CH}_{3} \mathrm{OH}$ & methanol & 376.98 & 128.31 & 6.87 & -0.44 & 0.31 & 0.01 & 1.43 & -0.46 & -0.31 & 0.13 & 0.04 & 512.86 \\
\hline $\mathrm{C}_{2} \mathrm{H}_{5} \mathrm{OH}$ & ethanol & 607.58 & 190.64 & 10.56 & $-0.69^{b}$ & $0.46^{d}$ & $0.02^{e}$ & 2.63 & -0.65 & -0.39 & 0.19 & 0.07 & 810.39 \\
\hline $\mathrm{H}(\mathrm{O}=) \mathrm{C}-\mathrm{C}(=\mathrm{O}) \mathrm{H}$ & glyoxal & 436.32 & 178.80 & 17.15 & -1.23 & 1.31 & 0.08 & 2.62 & -0.65 & -0.62 & 0.07 & 0.09 & 633.91 \\
\hline trans- $\mathrm{H}(\mathrm{HO}) \mathrm{C}:$ & hydroxymethylene & 217.06 & 97.10 & 7.28 & -0.29 & 0.44 & 0.01 & 0.86 & -0.33 & -0.31 & 0.04 & 0.04 & 321.87 \\
\hline cis-H(HO)C: & hydroxymethylene & 211.87 & 97.39 & 7.40 & -0.29 & 0.45 & 0.01 & 0.81 & -0.32 & -0.31 & 0.02 & 0.04 & 317.04 \\
\hline $\mathrm{HN}=\mathrm{CH}$. & iminometyl radical & 220.02 & 105.66 & 8.77 & -0.43 & 0.63 & 0.05 & 1.51 & -0.32 & -0.08 & 0.05 & 0.07 & 335.90 \\
\hline $\mathrm{HOCN}$ & cyanic acid & 252.90 & 141.36 & 13.59 & -1.14 & 1.16 & 0.11 & 2.04 & -0.52 & -0.31 & 0.12 & 0.10 & 409.36 \\
\hline HONC: & isofulminic acid & 192.93 & 141.31 & 14.06 & -1.01 & 1.14 & 0.08 & 1.60 & -0.50 & -0.31 & 0.11 & 0.10 & 349.45 \\
\hline $\mathrm{HNCO}$ & isocyanic acid & 277.92 & 139.88 & 14.60 & -0.98 & 1.08 & 0.04 & 2.14 & -0.54 & -0.31 & 0.11 & 0.10 & 434.00 \\
\hline HCNO & formonitrile oxide & 193.26 & 151.69 & 17.30 & -1.39 & 1.69 & 0.10 & 2.26 & -0.57 & -0.31 & 0.10 & 0.10 & 364.20 \\
\hline cis- $\mathrm{H}_{2} \mathrm{~N}_{2}$ & diazene & 149.24 & 130.71 & 10.16 & -0.64 & 0.83 & 0.07 & 0.71 & -0.31 & 0.00 & 0.03 & 0.10 & 290.85 \\
\hline $\mathrm{HN}_{3}$ & hydrogen azide & 134.62 & 176.22 & 18.64 & -1.35 & 1.94 & 0.18 & 1.47 & -0.50 & 0.00 & 0.07 & 0.15 & 331.35 \\
\hline HNC: & hydrogen isocyanide & 194.77 & 93.05 & 8.79 & -0.57 & 0.64 & 0.05 & 1.45 & -0.26 & -0.08 & 0.09 & 0.07 & 297.95 \\
\hline trans $-\mathrm{HON}=\mathrm{O}$ & nitrous acid & 135.79 & 158.81 & 16.73 & -0.84 & 1.50 & 0.10 & 0.52 & -0.42 & -0.45 & 0.08 & 0.10 & 311.87 \\
\hline cis- $\mathrm{HON}=\mathrm{O}$ & nitrous acid & 136.24 & 158.11 & 16.65 & -0.91 & 1.47 & 0.10 & 0.51 & -0.42 & -0.45 & 0.08 & 0.10 & 311.44 \\
\hline $\mathrm{H}_{2} \mathrm{NCl}$ & chloramine & 147.94 & 92.63 & 6.85 & -0.43 & 0.48 & 0.02 & 0.55 & -0.39 & -0.84 & 0.09 & 0.06 & 246.92 \\
\hline trans- $\mathrm{HO}_{3}$ & hydrotrioxy radical & 58.53 & 153.82 & 18.44 & -0.20 & 2.33 & 0.18 & 0.17 & -0.31 & -0.67 & 0.06 & 0.07 & 232.38 \\
\hline cis- $\mathrm{HO}_{3}$. & hydrotrioxy radical & 62.62 & 151.22 & 17.20 & -0.34 & 2.04 & 0.15 & 0.18 & -0.31 & -0.67 & 0.06 & 0.07 & 232.18 \\
\hline $\mathrm{CH}_{3} \mathrm{~F}$ & fluoromethane & 319.78 & 96.78 & 5.32 & -0.29 & 0.19 & 0.01 & 1.17 & -0.38 & -0.47 & 0.08 & 0.03 & 422.19 \\
\hline $\mathrm{CH}_{2} \mathrm{~F}_{2}$ & difluoromethane & 319.29 & 109.46 & 7.98 & -0.52 & 0.33 & 0.01 & 1.11 & -0.54 & -0.85 & 0.07 & 0.03 & 436.34 \\
\hline $\mathrm{CF}_{4}$ & tetrafluoromethane & 330.49 & 134.31 & 13.25 & -1.02 & 0.62 & $0.02^{f}$ & 1.07 & -0.85 & -1.63 & 0.07 & 0.04 & 476.36 \\
\hline $\mathrm{SiH}_{3} \mathrm{~F}$ & fluorosilane & 302.49 & 77.36 & 3.09 & -0.38 & 0.12 & 0.00 & 0.06 & -0.95 & -0.81 & 0.01 & 0.01 & 381.00 \\
\hline $\mathrm{SiF}_{4}$ & tetrafluorosilane & 448.41 & 119.07 & 10.12 & -1.14 & 0.46 & $0.00^{f}$ & 0.84 & -1.90 & -1.97 & 0.05 & 0.03 & 573.96 \\
\hline $\mathrm{C}_{2} \mathrm{H}_{3} \mathrm{~F}$ & fluoroethylene & 428.27 & 132.97 & 10.23 & -0.65 & 0.58 & 0.03 & 2.44 & -0.51 & -0.55 & 0.12 & 0.05 & 572.95 \\
\hline $\mathrm{C}_{2} \mathrm{H}_{5} \mathrm{~F}$ & fluoroethane & 551.42 & 158.87 & 8.97 & $-0.52^{b}$ & $0.34^{d}$ & $0.02^{e}$ & 2.38 & -0.56 & -0.55 & 0.14 & 0.05 & 720.53 \\
\hline $\mathrm{FC} \equiv \mathrm{CF}$ & difluoroacetylene & 247.55 & 121.94 & 13.68 & -1.12 & 1.02 & 0.08 & 2.91 & -0.72 & -0.94 & 0.08 & 0.05 & 384.50 \\
\hline $\mathrm{HC} \equiv \mathrm{CF}$ & fluoroacetylene & 276.39 & 108.31 & 11.07 & -0.93 & 0.86 & 0.07 & 2.68 & -0.49 & -0.55 & 0.10 & 0.05 & 397.53 \\
\hline $\mathrm{HC}(=\mathrm{O}) \mathrm{F}$ & formylfluoride & 277.02 & 114.27 & 11.08 & -0.74 & 0.69 & 0.03 & 1.37 & -0.49 & -0.69 & 0.06 & 0.05 & 402.62 \\
\hline $\mathrm{F}_{2} \mathrm{C}=\mathrm{O}$ & carbonyl fluoride & 279.65 & 126.11 & 13.54 & -1.01 & 0.82 & 0.03 & 1.47 & -0.67 & -1.08 & 0.06 & 0.06 & 418.95 \\
\hline $\mathrm{H}_{2} \mathrm{C}:\left({ }^{1} A_{1}\right)$ & methylene & 130.07 & 48.76 & 1.90 & 0.20 & 0.12 & 0.00 & 0.39 & -0.09 & -0.08 & -0.10 & 0.02 & 181.18 \\
\hline
\end{tabular}

${ }^{a}$ Difference between the MOLPRO and ACES II definitions of the valence ROCCSD(T), half of this contribution is added to the final TAE as discussed in the appendix of ref. 24]. ${ }^{b}$ The CCSDT calculation is carried out with the PVTZ(no $d$ on H), see computational details. ${ }^{c}$ The $\hat{T}_{4}$ contribution is taken from W4lite theory, see computational details. ${ }^{d}$ The CCSDTQ calculation is carried out with the PVDZ(no $p$ on $\mathrm{H}$ ), see computational details. ${ }^{e}$ The $\hat{T}_{5}$ contribution is approximated as $\operatorname{CCSDTQ}(5)_{\Lambda} / \mathrm{cc}-\mathrm{pVDZ}($ no $d)-\mathrm{CCSDTQ} / \mathrm{cc}-\mathrm{pVDZ}($ no $d)$. ${ }^{f}$ Estimating $\hat{T}_{5}$ for $\mathrm{XF}_{4}(\mathrm{X}=\mathrm{C}, \mathrm{Si})$ from the isodesmic $4 \mathrm{XFH}_{3} \rightarrow \mathrm{XF}_{4}+3 \mathrm{XH}_{4}$ reaction, assuming that the reaction energy is converged at the CCSDTQ level. 
TABLE V: Comparison between W2.2, W3.2, W4lite, and W4 total atomization energies at $0 \mathrm{~K}$ and experimental determinations from Active Thermochemical Tables ( $\mathrm{TAE}_{0}$, in kcal $\left./ \mathrm{mol}\right)$.

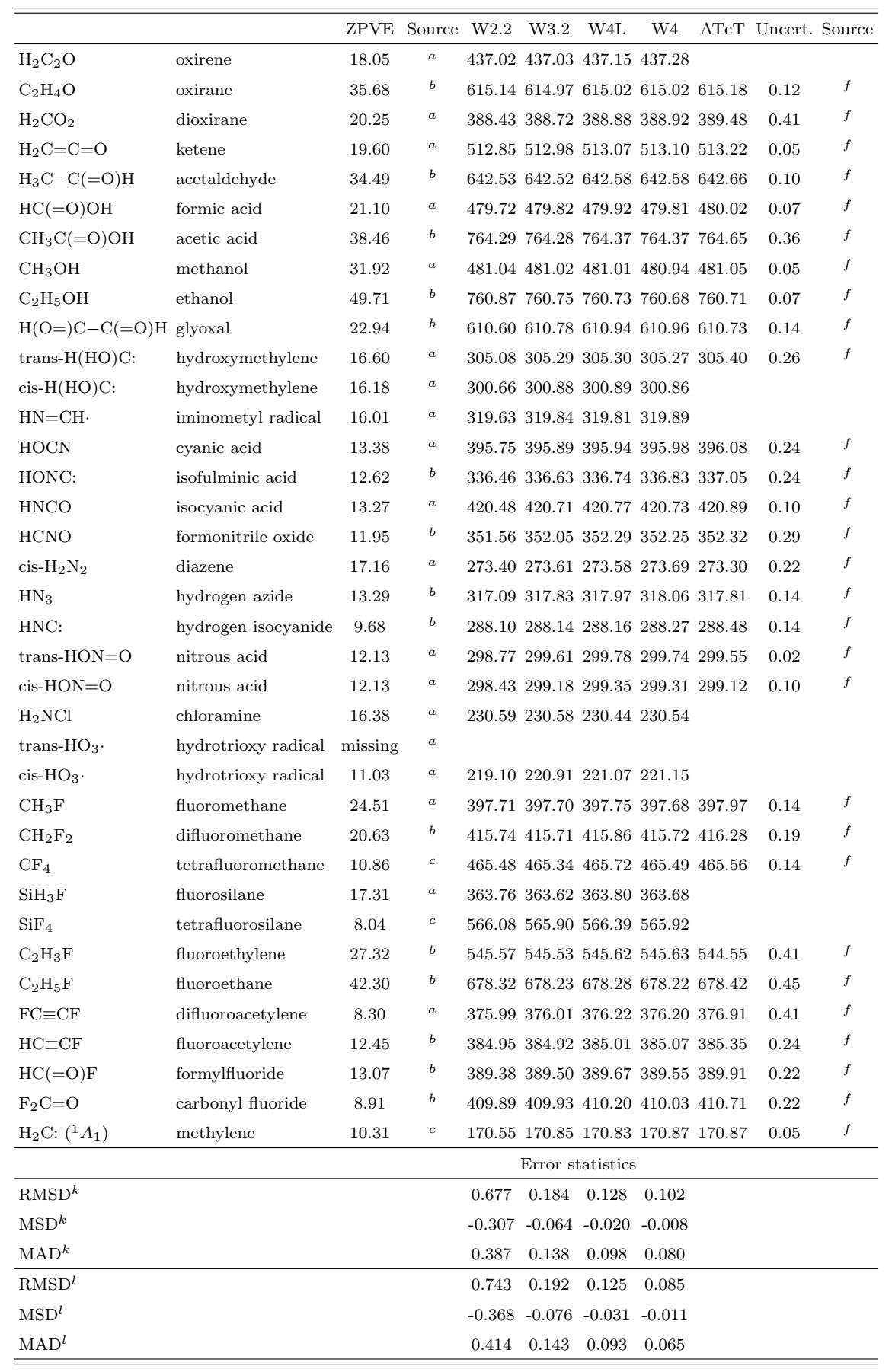

${ }^{a}$ ZPVE calculated as prescribed in ref. 43]. ${ }^{b} \mathrm{ZPVE}$ taken from ref. 106]. ${ }^{c} \mathrm{ZPVE}$ for $\mathrm{CF}_{4}$ and $\mathrm{SiF}_{4}$ from[119], and for $\mathrm{H}_{2} \mathrm{C}$ $\left({ }^{1} A_{1}\right)$ from ref. 120]. ${ }^{d}$ ZPVE taken from ref. [3]. ${ }^{e}$ ZPVE taken the W4-08 from ref. [8. ${ }^{f}$ ATcT taken from ref. [106]. ${ }^{g}$ ATcT taken from ref. 107. ${ }^{h} \mathrm{ATcT}$ taken from ref. 24]. ${ }^{i} \mathrm{ATcT}$ taken from ref. 25. ${ }^{j} \mathrm{ATcT}$ taken from ref. 104. ${ }^{k}$ Error statistics over the $45 \mathrm{ATcT} \mathrm{TAE}_{0}$ with associated uncertainty $\leq 0.10 \mathrm{kcal} / \mathrm{mol}$ (excluding hydrazine). ${ }^{l}$ Error statistics over the 35 ATcT $\mathrm{TAE}_{0}$ with associated uncertainty $\leq 0.05 \mathrm{kcal} / \mathrm{mol}$ (excluding hydrazine). 
TABLE VI: Performance of a representative set of DFT and composite thermochemical procedures for the 140 atomization reactions of the W4-11 dataset and for the DBH24 dataset of barrier heights. $^{a, b}$

\begin{tabular}{|c|c|c|c|c|c|c|c|c|c|c|c|}
\hline \multirow[t]{2}{*}{ Type } & \multirow[t]{2}{*}{ Method } & \multicolumn{3}{|c|}{ non MR (124 syst.) } & \multicolumn{3}{|c|}{ MR (16 syst.) } & \multicolumn{3}{|c|}{ All (140 syst.) } & \multirow{2}{*}{$\begin{array}{l}\text { DBH } 24^{c} \\
\text { RMSD }\end{array}$} \\
\hline & & RMSD & MSD & MAD & RMSD & MSD & MAD & RMSD & MSD & MAD & \\
\hline LDA & SVWN5 & 66.1 & 58.5 & 58.5 & 75.0 & 67.3 & 67.3 & 67.2 & 59.5 & 59.5 & 16.9 \\
\hline \multirow[t]{4}{*}{ GGA } & B97-D & 4.3 & 0.4 & 2.9 & 12.2 & 6.1 & 10.4 & 5.8 & 1.1 & 3.7 & 7.2 \\
\hline & BLYP & 9.0 & 3.7 & 6.6 & 19.2 & 13.7 & 15.5 & 10.7 & 4.8 & 7.6 & 8.9 \\
\hline & НCTH407 & 5.9 & 0.0 & 4.6 & 14.9 & 9.4 & 12.6 & 7.5 & 1.1 & 5.5 & 6.8 \\
\hline & PBE & 16.9 & 12.5 & 13.8 & 29.8 & 25.7 & 26.0 & 18.8 & 14.0 & 15.2 & 10.1 \\
\hline \multirow[t]{3}{*}{ MGGA } & M06-L & 5.3 & 0.9 & 4.0 & 6.8 & 2.4 & 5.3 & 5.5 & 1.0 & 4.1 & 5.4 \\
\hline & TPSS & 5.7 & 3.1 & 4.5 & 12.6 & 7.7 & 11.0 & 6.8 & 3.7 & 5.2 & 9.3 \\
\hline & $\tau$-HCTH & 4.7 & -0.1 & 3.6 & 13.1 & 7.4 & 10.9 & 6.2 & 0.7 & 4.5 & 7.3 \\
\hline \multirow[t]{7}{*}{ HGGA } & BH\&HLYP & 21.8 & -18.5 & 18.6 & 41.7 & -38.7 & 38.7 & 24.9 & -20.8 & 20.9 & 2.9 \\
\hline & B3LYP & 4.3 & -0.7 & 3.2 & 9.0 & -4.2 & 5.8 & 5.1 & -1.1 & 3.5 & 4.9 \\
\hline & B3P86 & 13.0 & 10.7 & 11.0 & 10.5 & 5.2 & 9.1 & 12.8 & 10.1 & 10.8 & 5.9 \\
\hline & B3PW91 & 3.7 & -0.6 & 2.6 & 7.8 & -2.1 & 4.8 & 4.4 & -0.7 & 2.9 & 4.6 \\
\hline & X3LYP & 4.1 & -0.6 & 3.0 & 9.2 & -4.8 & 5.8 & 4.9 & -1.1 & 3.3 & 4.9 \\
\hline & B97-1 & 4.0 & 0.0 & 3.1 & 8.2 & 1.0 & 6.1 & 4.7 & 0.1 & 3.4 & 4.4 \\
\hline & PBE0 & 4.1 & -0.7 & 3.1 & 8.2 & -3.3 & 4.6 & 4.8 & -1.0 & 3.3 & 4.5 \\
\hline \multirow[t]{2}{*}{ RSHGGA } & $\omega \mathrm{B} 97$ & 3.1 & -1.2 & 2.4 & 15.4 & -9.6 & 10.3 & 6.0 & -2.1 & 3.3 & 3.2 \\
\hline & $\omega \mathrm{B} 97-\mathrm{X}$ & 2.4 & -0.9 & 1.9 & 13.5 & -8.7 & 9.0 & 5.1 & -1.8 & 2.7 & 2.4 \\
\hline \multirow[t]{8}{*}{ HMGGA } & TPSSh & 5.5 & -1.0 & 4.2 & 8.4 & -2.5 & 5.1 & 5.9 & -1.2 & 4.3 & 7.3 \\
\hline & B1B95 & 3.0 & -0.4 & 2.2 & 8.0 & -2.8 & 4.5 & 3.9 & -0.7 & 2.5 & 3.2 \\
\hline & PW6B95 & 2.5 & 0.3 & 1.8 & 8.0 & -3.6 & 4.4 & 3.6 & -0.1 & 2.1 & 3.4 \\
\hline & $\tau$-HCTHh & 3.9 & 0.0 & 3.0 & 9.4 & 2.9 & 7.6 & 4.8 & 0.4 & 3.6 & 5.4 \\
\hline & BMK & 2.9 & 0.7 & 2.2 & 11.9 & -8.6 & 8.6 & 4.9 & -0.4 & 3.0 & 1.8 \\
\hline & M06 & 3.9 & 1.3 & 2.7 & 7.3 & -4.1 & 5.4 & 4.4 & 0.7 & 3.1 & 3.0 \\
\hline & M06-2X & 2.8 & -0.4 & 1.9 & 11.5 & -8.7 & 8.8 & 4.7 & -1.4 & 2.7 & 1.2 \\
\hline & M06-HF & 6.2 & -1.6 & 4.2 & 25.0 & -20.9 & 21.2 & 10.3 & -3.8 & 6.2 & 3.6 \\
\hline \multirow[t]{6}{*}{$\mathrm{DH}$} & B2GP-PLYP & 1.9 & -0.3 & 1.5 & 7.0 & -5.8 & 5.9 & 3.0 & -0.9 & 2.0 & 1.0 \\
\hline & B2K-PLYP & 2.3 & -0.9 & 1.7 & 9.7 & -8.3 & 8.3 & 3.9 & -1.8 & 2.5 & 1.3 \\
\hline & B2-PLYP & 2.7 & 0.9 & 1.9 & 3.4 & -1.4 & 2.1 & 2.8 & 0.6 & 1.9 & 2.3 \\
\hline & DSD-BLYP & 2.2 & 0.4 & 1.7 & 4.6 & -3.3 & 3.7 & 2.6 & 0.0 & 1.9 & 1.1 \\
\hline & mPW2-PLYP & 2.2 & -0.2 & 1.7 & 6.5 & -5.4 & 5.4 & 3.0 & -0.8 & 2.1 & 1.9 \\
\hline & ROB2-PLYP & 1.8 & 0.4 & 1.4 & 6.0 & -4.8 & 4.9 & 2.6 & -0.2 & 1.8 & 1.1 \\
\hline \multirow[t]{12}{*}{ COMPOSITE } & G3B3 & 2.0 & 0.2 & 1.5 & 3.2 & -1.9 & 2.4 & 2.1 & 0.0 & 1.6 & \\
\hline & G3(MP2)B3 & 2.0 & 0.3 & 1.5 & 3.1 & -1.6 & 2.6 & 2.2 & 0.1 & 1.7 & \\
\hline & CBS-QB3 & 1.9 & 1.2 & 1.5 & 2.1 & -0.2 & 1.5 & 1.9 & 1.0 & 1.5 & \\
\hline & ROCBS-QB3 & 1.8 & 0.9 & 1.4 & 1.6 & -0.4 & 1.3 & 1.8 & 0.8 & 1.4 & \\
\hline & G4 & 1.9 & 0.6 & 1.5 & 2.6 & -0.9 & 2.0 & 2.0 & 0.5 & 1.6 & \\
\hline & G4(MP2) & 1.8 & 0.8 & 1.5 & 2.9 & -0.2 & 2.2 & 2.0 & 0.7 & 1.5 & \\
\hline & G4(MP2)-6X & 1.10 & -0.26 & 0.79 & 2.34 & -0.24 & 1.81 & 1.28 & -0.26 & 0.89 & \\
\hline & $\mathrm{ccCA}$ & 1.08 & -0.54 & 0.72 & 2.20 & -1.75 & 1.90 & 1.25 & -0.67 & 0.84 & \\
\hline & ccCA-PS3 & 1.03 & -0.37 & 0.65 & 2.03 & -1.58 & 1.73 & 1.18 & -0.50 & 0.77 & \\
\hline & $\mathrm{W} 1 \mathrm{U}$ & 0.57 & 0.05 & 0.44 & 2.39 & -1.64 & 1.73 & 0.92 & -0.12 & 0.56 & \\
\hline & W1Usc & 0.69 & 0.07 & 0.52 & 2.81 & -1.85 & 1.95 & 1.09 & -0.12 & 0.66 & \\
\hline & W1RO & 0.65 & 0.05 & 0.48 & 2.20 & -1.56 & 1.66 & 0.92 & -0.11 & 0.59 & \\
\hline
\end{tabular}

${ }^{a} \mathrm{LDA}=$ local density approximation; GGA = general gradient approximation; MGGA = meta-GGA; HGGA = hybrid GGA; RSHGGA = range-separated HGGA; HMGGA = hybrid meta-GGA; DH = double hybrid; COMPOSITE = composite thermochemical procedures.

${ }^{b} \mathrm{RMSD}=$ root mean square deviation; $\mathrm{MSD}=$ mean signed deviation; $\mathrm{MAD}=$ mean absolute deviation. $\mathrm{A}$ positive MAD indicates overbinding (on average).

${ }^{c}$ For the performance of the composite methods for the DBH24 dataset, see refs. [121] and [122]. 
TABLE VII: Performance of a representative set of DFT and composite thermochemical procedures for the 99 bond dissociation reactions of the W4-11 dataset. ${ }^{a}$

\begin{tabular}{|c|c|c|c|}
\hline Method & RMSD & MSD & MAD \\
\hline SVWN5 & 28.9 & 25.7 & 25.7 \\
\hline B97-D & 4.7 & -0.2 & 3.9 \\
\hline BLYP & 6.2 & 1.0 & 4.8 \\
\hline НCTH 407 & 6.2 & 1.3 & 4.9 \\
\hline PBE & 10.0 & 6.3 & 8.0 \\
\hline M06-L & 5.6 & 0.8 & 4.1 \\
\hline TPSS & 5.2 & 0.1 & 4.3 \\
\hline$\tau$-HCTH & 5.3 & 0.8 & 4.3 \\
\hline BH\&HLYP & 13.9 & -10.0 & 11.4 \\
\hline B3LYP & 3.9 & -1.7 & 3.2 \\
\hline B3P86 & 4.7 & 3.0 & 3.6 \\
\hline B3PW91 & 3.9 & -0.6 & 3.3 \\
\hline X3LYP & 3.9 & -1.6 & 3.2 \\
\hline B97-1 & 3.2 & 0.4 & 2.6 \\
\hline PBE0 & 4.4 & -0.2 & 3.7 \\
\hline$\omega \mathrm{B} 97$ & 5.4 & -1.0 & 3.4 \\
\hline$\omega \mathrm{B} 97-\mathrm{X}$ & 4.5 & -0.9 & 3.0 \\
\hline TPSSh & 5.1 & -1.9 & 4.0 \\
\hline B1B95 & 3.8 & 0.3 & 2.8 \\
\hline PW6B95 & 3.6 & 0.1 & 2.7 \\
\hline$\tau$-HCTHh & 4.1 & 0.9 & 3.2 \\
\hline BMK & 4.1 & -0.4 & 2.9 \\
\hline M06 & 3.7 & 0.7 & 2.5 \\
\hline M06-2X & 4.2 & -0.9 & 2.7 \\
\hline M06-HF & 9.9 & -2.3 & 6.9 \\
\hline B2GP-PLYP & 3.3 & -0.7 & 2.5 \\
\hline B2K-PLYP & 4.1 & -0.9 & 2.8 \\
\hline B2-PLYP & 2.5 & -0.4 & 2.1 \\
\hline DSD-BLYP & 3.0 & 0.1 & 2.2 \\
\hline mPW2-PLYP & 2.9 & -1.0 & 2.4 \\
\hline ROB2-PLYP & 2.5 & -0.2 & 1.9 \\
\hline G3B3 & 1.3 & -0.5 & 0.9 \\
\hline G3(MP2)B3 & 1.4 & -0.7 & 1.0 \\
\hline G4 & 1.0 & 0.0 & 0.7 \\
\hline G4(MP2) & 1.1 & 0.1 & 0.8 \\
\hline G4(MP2)-6X & 1.5 & -1.0 & 1.1 \\
\hline CBS-QB3 & 1.9 & 1.1 & 1.5 \\
\hline ROCBS-QB3 & 1.6 & 0.7 & 1.3 \\
\hline $\mathrm{ccCA}$ & 0.8 & -0.2 & 0.6 \\
\hline ccCA-PS3 & 0.8 & -0.1 & 0.6 \\
\hline W1U & 1.2 & -0.1 & 0.5 \\
\hline W1Usc & 281.4 & 0.2 & 0.8 \\
\hline W1RO & 0.8 & 0.1 & 0.5 \\
\hline
\end{tabular}


TABLE VIII: Performance of a representative set of DFT and composite thermochemical procedures for the 707 heavy-atom transfer reactions of the W4-11 dataset. ${ }^{a}$

\begin{tabular}{|c|c|c|c|}
\hline Method & RMSD & MSD & MAD \\
\hline SVWN5 & 12.0 & -0.9 & 9.4 \\
\hline B97-D & 5.9 & -2.0 & 4.7 \\
\hline BLYP & 7.4 & -3.1 & 5.9 \\
\hline НCTH407 & 6.9 & -0.7 & 5.6 \\
\hline PBE & 8.0 & -1.5 & 6.6 \\
\hline M06-L & 5.3 & 1.6 & 4.2 \\
\hline TPSS & 6.5 & -1.9 & 5.3 \\
\hline$\tau$-HCTH & 6.3 & -0.6 & 5.1 \\
\hline BH\&HLYP & 9.7 & 1.8 & 7.7 \\
\hline B3LYP & 3.9 & -1.1 & 3.1 \\
\hline B3P86 & 4.0 & -0.5 & 3.2 \\
\hline B3PW91 & 4.3 & 0.0 & 3.4 \\
\hline X3LYP & 3.9 & -0.8 & 3.0 \\
\hline B97-1 & 3.7 & -0.3 & 3.0 \\
\hline PBE0 & 4.8 & 0.8 & 3.9 \\
\hline$\omega \mathrm{B} 97$ & 5.1 & -0.4 & 3.9 \\
\hline$\omega \mathrm{B} 97-\mathrm{X}$ & 4.4 & 0.0 & 3.4 \\
\hline TPSSh & 5.5 & -1.0 & 4.4 \\
\hline B1B95 & 3.9 & 0.2 & 3.1 \\
\hline PW6B95 & 3.6 & 0.1 & 2.8 \\
\hline$\tau$-HCTHh & 4.3 & -0.1 & 3.5 \\
\hline BMK & 5.0 & 0.7 & 3.8 \\
\hline M06 & 4.8 & 2.3 & 3.5 \\
\hline M06-2X & 4.6 & 0.6 & 3.3 \\
\hline M06-HF & 9.5 & -0.5 & 6.8 \\
\hline B2GP-PLYP & 3.1 & 1.0 & 2.4 \\
\hline B2K-PLYP & 4.1 & 1.6 & 3.2 \\
\hline B2-PLYP & 2 & 0.0 & 1.8 \\
\hline DSD-BLYP & 2.9 & 1.1 & 2.3 \\
\hline mPW2-PLYP & 2.7 & 0.5 & 2.1 \\
\hline ROB2-PLYP & 2.6 & 0.9 & 2.1 \\
\hline G3B3 & 1.5 & 0.2 & 1.1 \\
\hline G3(MP2)B3 & 1.8 & 0.0 & 1.4 \\
\hline G4 & 1.2 & 0.2 & 0.9 \\
\hline G4(MP2) & 1.5 & 0.1 & 1.2 \\
\hline G4(MP2)-6X & 1.5 & -0.7 & 1.2 \\
\hline CBS-QB3 & 2.3 & 0.6 & 1.5 \\
\hline ROCBS-QB3 & 1.8 & 0.3 & 1.4 \\
\hline $\mathrm{ccCA}$ & 1.0 & 0.0 & 0.8 \\
\hline ccCA-PS3 & 1.0 & 0.0 & 0.8 \\
\hline W1U & 1.8 & 0.4 & 1.0 \\
\hline W1Usc & $29_{2.1}$ & 0.6 & 1.4 \\
\hline W1RO & 1.3 & 0.4 & 0.9 \\
\hline
\end{tabular}


TABLE IX: Performance of a representative set of DFT and composite thermochemical procedures for the 20 isomerization reactions of the W4-11 dataset. ${ }^{a}$

\begin{tabular}{|c|c|c|c|}
\hline Method & RMSD & MSD & MAD \\
\hline SVWN5 & 5.8 & 0.3 & 4.2 \\
\hline B97-D & 3.7 & -0.5 & 2.7 \\
\hline BLYP & 3.9 & -0.6 & 2.9 \\
\hline НCTH 407 & 4.5 & 0.0 & 3.0 \\
\hline PBE & 4.3 & -0.6 & 2.9 \\
\hline M06-L & 3.9 & 0.4 & 2.8 \\
\hline TPSS & 4.3 & -1.3 & 3.0 \\
\hline$\tau$-HCTH & 3.9 & -0.5 & 2.7 \\
\hline BH\&HLYP & 3.2 & 0.9 & 2.6 \\
\hline B3LYP & 2.3 & 0.0 & 1.7 \\
\hline B3P86 & 2.5 & 0.1 & 1.9 \\
\hline B3PW91 & 2.5 & 0.1 & 1.8 \\
\hline X3LYP & 2.2 & 0.1 & 1.6 \\
\hline B97-1 & 2.1 & -0.3 & 1.5 \\
\hline PBE0 & 2.4 & 0.1 & 1.7 \\
\hline$\omega \mathrm{B} 97$ & 2.4 & 0.0 & 1.7 \\
\hline$\omega \mathrm{B} 97-\mathrm{X}$ & 2.2 & 0.2 & 1.6 \\
\hline TPSSh & 3.3 & -0.9 & 2.4 \\
\hline B1B95 & 2.1 & -0.1 & 1.6 \\
\hline PW6B95 & 2.0 & -0.6 & 1.4 \\
\hline$\tau$-HCTHh & 2.6 & -0.3 & 1.8 \\
\hline BMK & 2.3 & 0.0 & 1.7 \\
\hline M06 & 2.5 & 0.6 & 1.9 \\
\hline M06-2X & 1.5 & -0.6 & 1.2 \\
\hline M06-HF & 4.8 & -1.2 & 3.7 \\
\hline B2GP-PLYP & 3.0 & 1.1 & 2.0 \\
\hline B2K-PLYP & 3.4 & 1.3 & 2.3 \\
\hline B2-PLYP & 2.4 & 0.8 & 1.8 \\
\hline DSD-BLYP & 2.8 & 1.3 & 1.9 \\
\hline mPW2-PLYP & 2.4 & 0.9 & 1.7 \\
\hline ROB2-PLYP & 2.4 & 1.2 & 1.6 \\
\hline G3B3 & 0.3 & 0.1 & 0.3 \\
\hline G3(MP2)B3 & 0.5 & -0.1 & 0.3 \\
\hline G4 & 0.7 & 0.0 & 0.5 \\
\hline G4(MP2) & 0.9 & -0.1 & 0.7 \\
\hline G4(MP2)-6X & 1.0 & -0.3 & 0.7 \\
\hline CBS-QB3 & 0.5 & -0.2 & 0.4 \\
\hline ROCBS-QB3 & 0.4 & -0.1 & 0.4 \\
\hline $\mathrm{ccCA}$ & 0.4 & -0.1 & 0.3 \\
\hline ccCA-PS3 & 0.3 & -0.1 & 0.3 \\
\hline $\mathrm{W} 1 \mathrm{U}$ & 0.2 & 0.1 & 0.2 \\
\hline W1Usc & $30.2^{b}$ & 0.1 & 0.2 \\
\hline W1RO & 0.2 & 0.1 & 0.2 \\
\hline
\end{tabular}

${ }^{a}$ See footnotes $a$ and $b$ of Table VI ${ }^{b}$ Statistics exclude the $\mathrm{ClO}_{2}$ to ClOO isomerization due to anomalous value of the "sc" spin contamination correction 99 for the highly spin-contaminated ClOO radical. 
TABLE X: Performance of a representative set of DFT and composite thermochemical procedures for the 13 nucleophilic substitution reactions of the W4-11 dataset. ${ }^{a}$

\begin{tabular}{|c|c|c|c|}
\hline Method & RMSD & MSD & MAD \\
\hline SVWN5 & 14.4 & 13.0 & 13.0 \\
\hline B97-D & 4.2 & 3.6 & 3.6 \\
\hline BLYP & 5.2 & 4.3 & 4.3 \\
\hline НCTH407 & 5.6 & 5.4 & 5.4 \\
\hline PBE & 5.8 & 5.2 & 5.4 \\
\hline M06-L & 1.4 & -0.3 & 1.2 \\
\hline TPSS & 4.2 & 3.1 & 3.6 \\
\hline$\tau$-HCTH & 6.0 & 5.9 & 5.9 \\
\hline BH\&HLYP & 5.6 & -5.0 & 5.0 \\
\hline B3LYP & 2.4 & 0.9 & 2.3 \\
\hline B3P86 & 1.9 & 1.3 & 1.7 \\
\hline B3PW91 & 1.3 & 0.8 & 1.2 \\
\hline X3LYP & 2.1 & 0.8 & 2.0 \\
\hline B97-1 & 1.6 & 1.0 & 1.4 \\
\hline PBE0 & 1.4 & 0.1 & 1.0 \\
\hline$\omega \mathrm{B} 97$ & 1.4 & 0.5 & 1.1 \\
\hline$\omega \mathrm{B} 97-\mathrm{X}$ & 1.0 & 0.0 & 0.9 \\
\hline TPSSh & 2.8 & 1.1 & 2.8 \\
\hline B1B95 & 1.3 & 0.9 & 1.0 \\
\hline PW6B95 & 1.0 & 0.6 & 0.8 \\
\hline$\tau$-HCTHh & 3.0 & 2.8 & 2.8 \\
\hline BMK & 1.0 & 0.5 & 0.8 \\
\hline M06 & 2.3 & 2.1 & 2.1 \\
\hline M06-2X & 1.0 & 0.4 & 0.7 \\
\hline M06-HF & 2.0 & 0.1 & 1.7 \\
\hline B2GP-PLYP & 0.7 & 0.3 & 0.6 \\
\hline B2K-PLYP & 0.4 & 0.0 & 0.3 \\
\hline B2-PLYP & 1.4 & 0.9 & 1.2 \\
\hline DSD-BLYP & 0.8 & 0.7 & 0.7 \\
\hline mPW2-PLYP & 0.9 & 0.2 & 0.8 \\
\hline ROB2-PLYP & 0.7 & 0.4 & 0.6 \\
\hline G3B3 & 0.5 & -0.2 & 0.4 \\
\hline G3(MP2)B3 & 0.6 & 0.0 & 0.4 \\
\hline G4 & 0.5 & -0.4 & 0.4 \\
\hline G4(MP2) & 0.6 & -0.5 & 0.5 \\
\hline G4(MP2)-6X & 0.8 & 0.6 & 0.7 \\
\hline CBS-QB3 & 0.3 & 0.1 & 0.2 \\
\hline ROCBS-QB3 & 0.3 & 0.0 & 0.2 \\
\hline $\mathrm{ccCA}$ & 0.2 & 0.0 & 0.1 \\
\hline ccCA-PS3 & 0.2 & 0.1 & 0.2 \\
\hline W1U & 0.3 & 0.3 & 0.3 \\
\hline W1Usc & $31_{0.3}$ & 0.3 & 0.3 \\
\hline W1RO & 0.3 & 0.3 & 0.3 \\
\hline
\end{tabular}




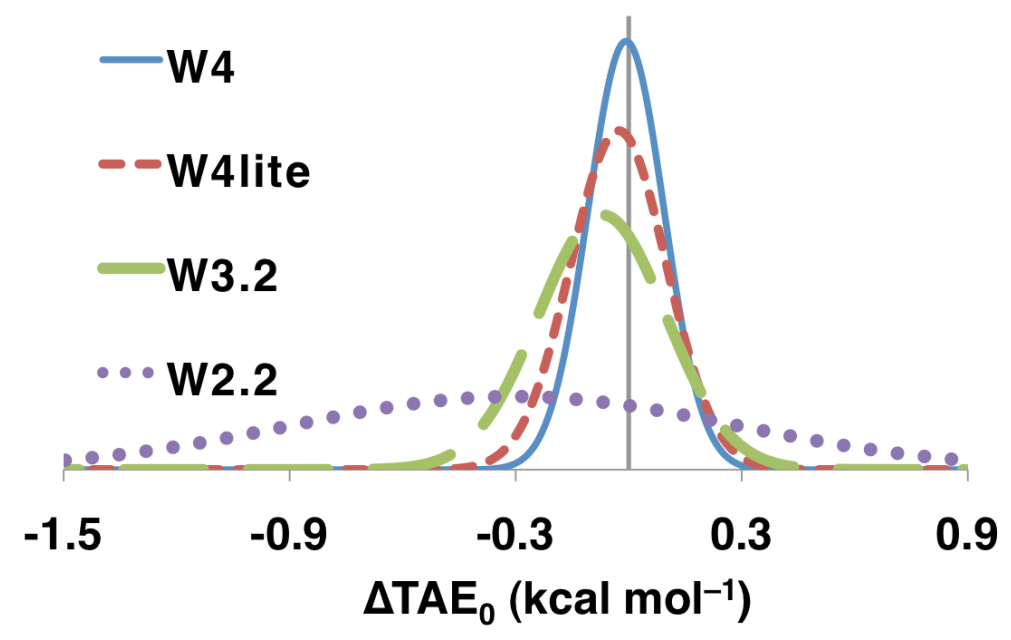

FIG. 1: Normal distribution of errors between the Wn methods and experiment for a set of 45 atomization energies $\left(\mathrm{TAE}_{0}\right)$ for which highly accurate ATcT values are available. The Gaussians are centered around -0.008 (W4), -0.020 (W4lite), -0.064 (W3.2), and $-0.307 \mathrm{kcal} / \mathrm{mol}$ (W2.2). 


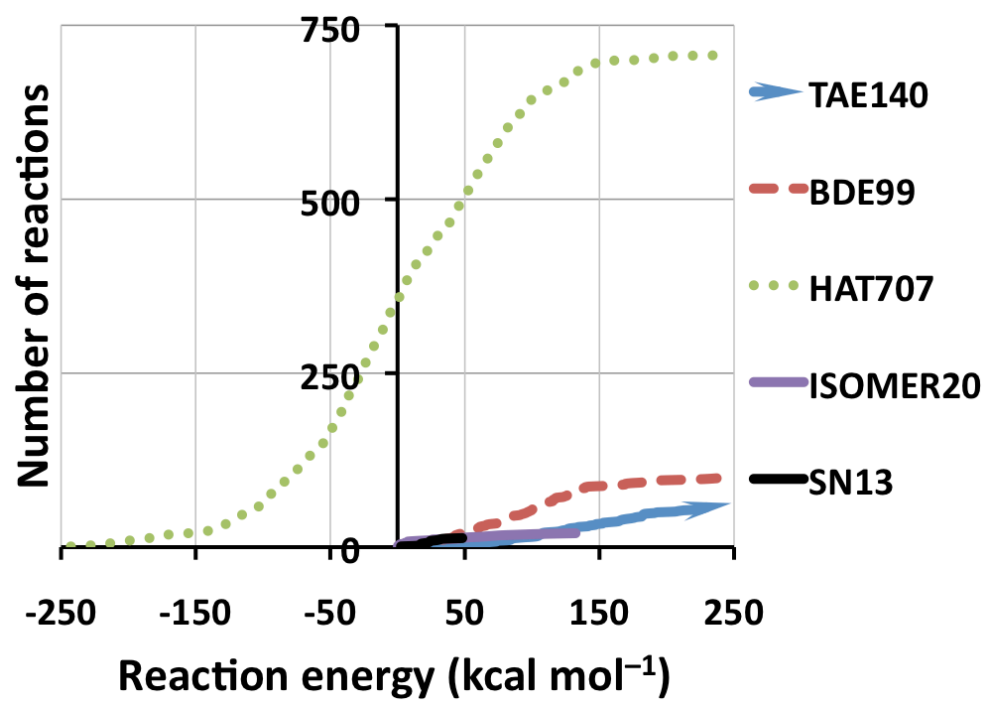

FIG. 2: Reaction energy distribution of the five subsets in the W4-11 dataset (note that the TAE140 subset spans a wider range of reaction energies, of up to $1007.9 \mathrm{kcal} / \mathrm{mol}$ ). 


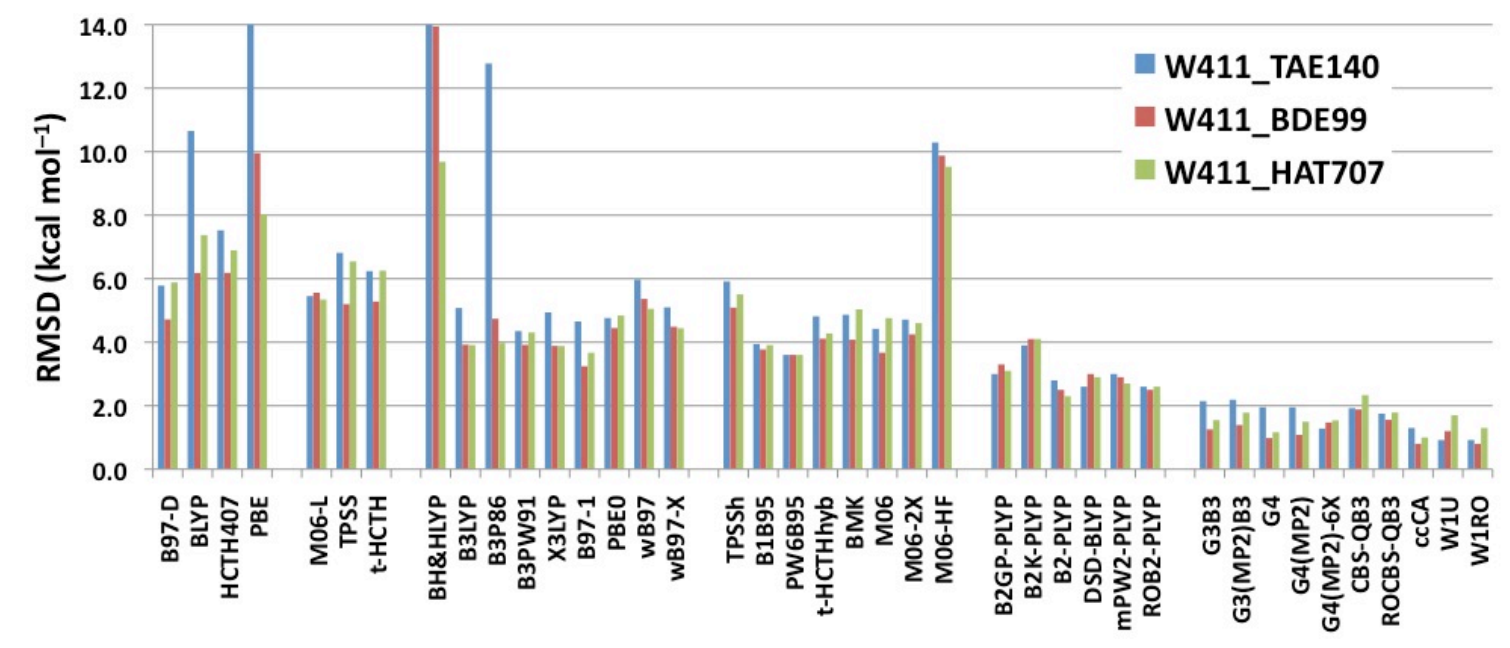

FIG. 3: Root mean square deviations (in $\mathrm{kcal} / \mathrm{mol}$ ) for DFT and composite thermochemical procedures over the TAE140, BDE99, and HAT107 subsets of the W4-11 database. 
[1] J.P. Perdew, K. Burke, M. Ernzerhof, Phys. Rev. Lett. 77 (1996) 3865; erratum 78 (1997) 1396.

[2] J.M. Tao, J.P. Perdew, V. N. Staroverov, G.E. Scuseria, Phys. Rev. Lett. 91 (2003) 146401.

[3] A.D. Becke, J. Chem. Phys. 98 (1993) 5648.

[4] F.A. Hamprecht, A.J. Cohen, D.J. Tozer, N.C. and Handy, J. Chem. Phys. 109 (1998) 6264.

[5] Y. Zhao, D.G. Truhlar, Theor. Chem. Acc. 120 (2007) 215.

[6] Y. Zhao, D.G. Truhlar, Acc. Chem. Res. 41 (2008) 157.

[7] Y. Zhao, D.G. Truhlar, J. Phys. Chem. A 110 (2006) 13126.

[8] A. Karton, A. Tarnopolsky, J.-F. Lamère, G.C. Schatz, J.M.L. Martin, J. Phys. Chem. A $112(2008) 12868$.

[9] J. A. Pople, M. Head-Gordon, D. J. Fox, K. Raghavachari, and L. A. Curtiss, J. Chem. Phys. 90, 5622 (1989); L. A. Curtiss, C. Jones, G. W. Trucks, K. Raghavachari, and J. A. Pople, J. Chem. Phys. 93, 2537 (1990).

[10] L.A. Curtiss, K. Raghavachari, G. W. Trucks, and J. A. Pople, Journal of Chemical Physics 94, $7221(1991)$

[11] L.A. Curtiss, K. Raghavachari, P. C. Redfern, V. Rassolov, and J. A. Pople, J. Chem. Phys. $109,7764(1998)$

[12] L.A. Curtiss, P.C. Redfern, K. Raghavachari, J. Chem. Phys. 126 (2007) 84108.

[13] Mayhall NJ, Raghavachari K, Redfern PC, Curtiss LA. J Phys Chem A. 2009 Apr $30 ; 113(17): 5170-5$.

[14] The G2/97, G3/99, and G3/05 datasets are available in machine-readable form from the website of Larry A. Curtiss at Argonne National Laboratory, http://www.cse.anl.gov/ Catalysis_and_Energy_Conversion/Computational_Thermochemistry.shtml

[15] "G2, G3 and associated quantum chemical models for accurate theoretical thermochemistry", K. Raghavachari and L. A. Curtiss, in Theory and applications of computational chemistry: The first 40 years, C. E. Dykstra, K. S. Kim, G. Frenking, and G. E. Scuseria, Eds., Elsevier Science, Amsterdam (2005), pp 785-812.

[16] P.J. Stephens, F.J. Devlin, C.F. Chabalowski, M.J. Frisch, J. Phys. Chem. 98 (1994) 11623.

[17] L. A. Curtiss, K. Raghavachari, P. C. Redfern, and J. A. Pople, Journal of Chemical Physics 
106, 1063 (1997); L. A. Curtiss, P. C. Redfern, K. Raghavachari, and J. A. Pople, Journal of Chemical Physics, 109, 42 (1998).

[18] L. A. Curtiss, K. Raghavachari, P. C. Redfern, and J. A. Pople, Journal of Chemical Physics, $112,7374(2000)$.

[19] L. A. Curtiss, P. C. Redfern, and K. Raghavachari, J. Chem. Phys. 123, 124107 (2005).

[20] M.W. Chase, Jr., C.A. Davies, J.R. Downey, Jr., D.J. Frurip, R.A. McDonald, and A.N. Syverud, JANAF Thermochemical Tables, Third Edition (1985); webified version available as NIST Standard Reference Database 13 at http://kinetics.nist.gov/janaf/

[21] NIST WebBook: NIST Standard Reference Database 69 (NIST, Gaithersburg, MD), Ed. P.J.Linstrom and W.G. Mallard. http://webbook.nist.gov/chemistry

[22] R. D. Johnson III, Computational Chemistry Comparison and Benchmark DataBase, Release 15a (April 2010), NIST Standard Reference Database 101, http://cccbdb.nist.gov/

[23] For a review of semiempirical methods, see: J. J. P. Stewart, in Reviews in Computational Chemistry, Vol. 1 (Eds. K. B. Lipkowitz and D. B. Boyd), Wiley, Hoboken, NJ, USA. http: //dx.doi.org/10.1002/9780470125786.ch2 See also: Stewart J. J. P., J. Mol. Modeling 13, 1173-1213 (2007).

[24] A. Karton, E. Rabinovich, J.M.L. Martin, B. Ruscic, J. Chem. Phys. 125 (2006) 144108.

[25] A. Karton, P.R. Taylor, J.M.L. Martin, J. Chem. Phys. 127 (2007) 064104.

[26] A. Tajti, P.G. Szalay, A.G. Császár, M. Kalláy, J. Gauss, E.F. Valeev, B.A. Flowers, J. Vázquez, J.F. Stanton, J. Chem. Phys. 121 (2004) 11599.

[27] Y.J. Bomble, J. Vázquez, M. Kállay, C. Michauk, P.G. Szalay, A.G. Császár, J. Gauss, J.F. Stanton, J. Chem. Phys. 125 (2006) 064108.

[28] M.E. Harding, J. Vázquez, B. Ruscic, A.K. Wilson, J. Gauss, J.F. Stanton, J. Chem. Phys. $128(2008) 114111$.

[29] T. Helgaker, W. Klopper, D.P. Tew, Mol. Phys. 106 (2008) 2107.

[30] D. Feller, K.A. Peterson, D.A. Dixon, J. Chem. Phys. 129 (2008) 204105.

[31] B. Ruscic, R.E. Pinzon, M.L. Morton, G. von Laszewski, S. Bittner, S.G. Nijsure, K.A. Amin, M. Minkoff, A.F. Wagner, J. Phys. Chem. A 108 (2004) 9979.

[32] B. Ruscic, Encyclopedia of Science and Technology (2005 Yearbook of Science and Technology), McGraw-Hill, New York, 2004, pp. 3-7.

[33] B. Ruscic, R.E. Pinzon, M.L. Morton, N.K. Srinivasan, M.-C. Su, J.W. Sutherland, J.V. 
Michael, J. Phys. Chem. A 110 (2006) 6592.

[34] Y. Zhao, D.G. Truhlar, J. Chem. Theory Comput. 1 (2005) 415.

[35] Y. Zhao, N.E. Schultz, D.G. Truhlar, J. Chem. Theory Comput. 2 (2006) 364.

[36] Y. Zhao, N.E. Schultz, D.G. Truhlar, J. Chem. Phys. 123 (2005) 161103.

[37] Y. Zhao, D.G. Truhlar, J. Phys. Chem. A 109 (2005) 5656.

[38] J. Zheng, Y. Zhao, D.G. Truhlar, J. Chem. Theory Comput. 3 (2007) 569.

[39] (69) Zhao, Y.; Gonza?lez-Garc?a, N.; Truhlar, D. G. J. Phys. Chem. A 2005, 109, 2012(erratum 2006, 110, 4942)

[40] J. Zheng, Y. Zhao, D.G. Truhlar, J. Chem. Theory Comput. 5 (2009) 808.

[41] P. Jurecka, J. Sponer, J. Cerny, P. Hobza, Phys Chem Chem Phys 8 (2006) 1985.

[42] L. Gráfová, M. Pitonák, J. Rezác, P. Hobza, J. Chem. Theory Comput. 6 (2010) 2365; see also http: //www. begdb.com.

[43] A. Karton, D. Gruzman, J.M.L. Martin, J. Phys. Chem. A 113 (2009) 8434.

[44] D. Gruzman, A. Karton. J.M.L. Martin, J. Phys. Chem. A 113 (2009) 11974.

[45] L. Goerigk, S. Grimme, J. Chem. Theory Comput. 7 (2011) 291.

[46] S. Korth and S. Grimme, J. Chem. Theory Comput., 2009, 5 (4), pp 9931003

[47] MOLPRO, version 2009.1, a package of ab initio programs, H.-J. Werner et al., see http: //www.molpro.net.

[48] MRCC, a string-based general coupled cluster program suite written by M. Kállay, see also: http://www.mrcc.hu

[49] M. Kállay, P.R. Surján, J. Chem. Phys. 115 (2001) 2945.

[50] CFOUR, a quantum chemical program package written by J. F. Stanton et al., see also: http://www.cfour.de

[51] T.H. Dunning, J. Chem. Phys. 90 (1989) 1007.

[52] R.A. Kendall, T.H. Dunning, R.J. Harrison, J. Chem. Phys. 96 (1992) 6796.

[53] T.H. Dunning, K.A. Peterson, A.K. Wilson, J. Chem. Phys. 114, (2001) 9244.

[54] K.A. Peterson, T.H. Dunning, J. Chem. Phys. 117 (2002) 10548.

[55] W.A. de Jong, R.J. Harrison, D.A. Dixon, J. Chem. Phys. 114 (2001) 48.

[56] A. Karton, J.M.L. Martin, Theor. Chem. Acc. 115 (2006) 330.

[57] F. Jensen, Theor. Chem. Acc. 113 (2005) 267.

[58] W. Klopper, Mol. Phys. 99 (2001) 481. 
[59] P.J. Knowles, C. Hampel, H.-J. Werner, J. Chem. Phys. 99 (2000) 5219; erratum 112 (2000) 3106.

[60] J.D. Watts, J. Gauss, R.J. Bartlett, J. Chem. Phys. 98 (1993) 8718.

[61] M. Douglas, N.M. Kroll, Ann. Phys. 82 (1974) 89.

[62] B.A. Heß, Phys. Rev. A 33 (1986) 3742.

[63] A. Karton, I. Kaminker, J.M.L. Martin, J. Phys. Chem. A 113 (2009) 7610.

[64] J.P. Perdew, K. Schmidt, AIP Conference Proceedings 577 (2001) 1.

[65] S.H. Vosko, L. Wilk, M. Nusair, Can. J. Phys. 58 (1980) 1200.

[66] S. Grimme, J. Comp. Chem. 27 (2006) 1787.

[67] A.D. Becke, Phys. Rev. A 38 (1988) 3098.

[68] C. Lee, W. Yang, R.G. Parr, Phys. Rev. B 37 (1988) 785.

[69] A.D. Boese, N.C. Handy, J. Chem. Phys. 114 (2001) 5497.

[70] Y. Zhao, D.G. Truhlar, J. Chem. Phys. 125 (2006) 194101.

[71] A.D. Boese, N.C. Handy, J. Chem. Phys. 116 (2002) 9559.

[72] A.D. Becke, J. Chem. Phys. 98 (1993) 1372.

[73] J.P. Perdew, Phys. Rev. B 33 (1986) 8822.

[74] J.P. Perdew, J.A. Chevary, S.H. Vosko, K.A. Jackson, M.R. Pederson, D.J. Singh, and C. Fiolhais, Phys. Rev. B 46 (1992) 6671.

[75] X. Xu, Q. Zhang, R.P. Muller, W.A. Goddard III, J. Chem. Phys. 122 (2005) 014105.

[76] C. Adamo, V. Barone, J. Chem. Phys. 110 (1999) 6158.

[77] J.-D. Chai, M. Head-Gordon, J. Chem. Phys. 128 (2008) 084106.

[78] V. N. Staroverov, G.E. Scuseria, J. Tao, J.P. Perdew, J. Chem. Phys. 119 (2003) 12129.

[79] Combines Becke88[67] exchange functional (28\% HF exchange) and Becke95[123] correlation functional.

[80] A.D. Boese, J.M.L. Martin, J. Chem. Phys. 121 (2004) 3405.

[81] S. Grimme, J. Chem. Phys. 124 (2006) 034108.

[82] D.C. Graham, A.S. Menon, L. Goerigk, S. Grimme, L. Radom, J. Phys. Chem. A 113 (2009) 9861.

[83] T. Schwabe, S. Grimme, Phys. Chem. Chem. Phys. 8 (2006) 4398.

[84] A. Tarnopolsky, A. Karton, R. Sertchook, D. Vuzman, J.M.L. Martin, J. Phys. Chem. A 112 (2008) 3 . 
[85] S. Kozuch, D. Gruzman, J.M.L. Martin, J. Phys. Chem C 114 (2010) 20801.

[86] F. Jensen, J. Chem. Phys. 115 (2001) 9113; erratum, 116 (2002) 3502.

[87] J.M.L. Martin, Mol. Struct. (Theochem) 771 (2006) 19.

[88] A.G. Baboul, L.A. Curtiss, P.C. Redfern, K. Raghavachari, J. Chem. Phys. 110 (1999) 7650.

[89] L.A. Curtiss, P.C. Redfern, K. Raghavachari, J. Chem. Phys. 127 (2007) 124105.

[90] B. Chan, J. Deng, L. Radom, J. Chem. Theory Comput. 7 (2011) 112.

[91] J.A. Montgomery Jr, M.J. Frisch, J.W. Ochterski, G.A. Petersson, J. Chem. Phys. 110 (1999) 2822 .

[92] G.P.F. Wood, L. Radom, G.A. Petersson, E.C. Barnes, M.J. Frisch, J.A. Montgomery Jr. , J. Chem. Phys. 125 (2006) 094106.

[93] N. J. DeYonker, T. R. Cundari, A. K. Wilson J. Chem. Phys. 124 (2006) 114104.

[94] N. J. DeYonker, T. Grimes, S. Yockel, A. Dinescu, B. Mintz, T. R. Cundari, A. K. Wilson J. Chem. Phys. (2006) 125, 104111.

[95] For a review, see: N. DeYonker, T. R. Cundari, A. K. Wilson, in: Advances in the Theory of Atomic and Molecular Systems (Progress in Theoretical Chemistry and Physics, Vol. 19); Piecuch, P.; Maruani, J.; Delgado-Barrio, G.; Wilson, S., Eds.; Springer Netherlands: Dordrecht, 2009; Vol. 19, pp. 197-224.

[96] N. J. DeYonker, B. R. Wilson, A. W. Pierpont, T. R. Cundari, A. K. Wilson, Mol. Phys. 107 (2009) 1107.

[97] K. R Jorgensen, G. A. Oyedepo, A. K. Wilson, J. Hazardous Mat. 186 (2011) 583.

[98] J. M. L. Martin and G. de Oliveira, J. Chem. Phys. 111, 1843 (1999); see also S. Parthiban and J. M. L. Martin, J. Chem. Phys. 114, 6014 (2001) and J. M. L. Martin and S. Parthiban, in "Computational Thermochemistry. Prediction and Estimation of Molecular Thermodynamics" (Ed. J. Cioslowski), Understanding Chemical Reactivity, Vol. 22 (Kluwer, Dordrecht, 2001), pp.31-65. http://dx.doi.org/10.1007/0-306-47632-0

[99] E. C. Barnes, G. A. Petersson, J. A. Montgomery, M. J. Frisch, and Jan M. L. Martin, J. Chem. Theory Comput. 5 , 26872693 (2009)

[100] Gaussian 09, Revision B.2, Frisch, M. J. et al., Gaussian, Inc., Wallingford CT, see also: http://www.gaussian.com.

[101] T.J. Lee, J.E. Rice, G.E. Scuseria, H.F. Schaefer III, Theor. Chim. Acta 75 (1989) 81.

[102] T.J. Lee, Chem. Phys. Lett. 372 (2003) 362. 
[103] M.L. Leininger, I.M.B. Nielsen, T.D. Crawford, C.L. Janssen, Chem. Phys. Lett. 328 (2000) 431.

[104] A. Karton, S. Parthiban, J.M.L. Martin, J. Phys. Chem. A 113 (2009) 4802.

[105] For highly multireference systems, such as $\mathrm{O}_{3}, \mathrm{FO} \cdot \mathrm{FOO} \cdot \mathrm{F}_{2} \mathrm{O}_{2}$, and $\mathrm{ClOO} \cdot$ the differences range between $0.2-0.4 \%$. An extreme case for which this assumption clearly does not hold is the beryllium diatomic. The contributions to the atomization energy from W4.3 theory are: -6.79 (SCF), $6.04(\mathrm{CCSD}), 2.61((\mathrm{~T})), 0.41\left(\hat{T}_{3}-(\mathrm{T})\right), 0.24\left(\hat{T}_{4}\right)$, and $0.00 \mathrm{kcal} / \mathrm{mol}\left(\hat{T}_{5}\right)$. Therefore, $\mathrm{Be}_{2}$ is unbound both at the SCF and CCSD levels and we obtain an artificially high $\% \operatorname{TAE}_{e}[(\mathrm{~T})]$ values of $104.5 \%$ with respect to the CCSDTQ5 TAE, and \% $\mathrm{TAE}_{e}[(\mathrm{~T})]=$ $140.6 \%$ with respect to the $\operatorname{CCSD}(\mathrm{T})$ TAE.

[106] W. Klopper, B. Ruscic; D.P. Tew, F.A. Bischoff, S. Wolfsegger, Chem. Phys. 356 (2009) 14.

[107] Based on early beta version 1.110 of the Core (Argonne) Thermochemical Network, see also: http://atct.anl.gov/Thermochemical\%20Data/version\%20earlyBeta\%201.110/ index.html.

[108] W. Klopper, R.A. Bachorz, C. Hättig, D.P. Tew, Theor. Chem. Acc. 126 (2010) 289.

[109] A. Karton, J.M.L. Martin, J. Chem. Phys. 133 (2010) 144102.

[110] S.E. Wheeler, K.N. Houk, P.v.R. Schleyer, W.D. Allen, J. Am. Chem. Soc. 131 (2009) 2547.

[111] P. J. Huber, "Robust statistics" (Wiley-IEEE, 2004), p. 108.

[112] A. S. Eddington, "Stellar movements and the structure of the Universe" (Macmillan, London, 1914)

[113] R. A. Fisher, "A mathematical examination of the methods of determining the accuracy of an observation by the mean error and the mean square error", Mon. Not. Royal Astron. Soc. $80(1920) 758$.

[114] R. C. Geary, Biometrika 27 (1935) 310.

[115] R. C. Geary, Biometrika 28 (1936) 295.

[116] C. Willmott, K. Matsuura, Climate Research 30 (2005) 79-82.

[117] 51 M. W. Feyereisen, G. Fitzgerald, and A. Kormornicki, Chem. Phys. Lett. 208 (1993) 359; O. Vahtras, J. Almlof, and M. W. Feyereisen, Chem. Phys. Lett. 213 (1993) 514; R. Kendall, H. A. Früchtl, Theoretica Chimica Acta, 97 (1997) 158; F. Weigend, M. Häser, H. Patzelt and R. Ahlrichs; Chem. Phys. Letters 294 (1998) 143.

[118] B. P.Prascher, J. D., Lai, A. K. Wilson, J. Chem. Phys. 131 (2009) 044130. 
[119] X.-G. Wang, E.L. Sibert III, J.M.L. Martin, J. Chem. Phys. 112 (2000) 1353.

[120] G. Czaka, T. Furtenbacher, V. Szalay, A.G. Császár, B.T. Sutcliffe, J. Mol. Struct. 780 (2006) 283.

[121] L. A. Curtiss, P. C. Redfern, K. Raghavachari Chem. Phys. Lett. 499 (2010) 168.

[122] J. Zheng, Y. Zhao, D. G. Truhlar J. Chem. Theory Comput. 5 (2009) 808.

[123] A. D. Becke, J. Chem. Phys. 104 (1996) 1040. 